\title{
The Significance of Levallois and Discoidal Technology in the Arcadia Valley, South Central Queensland
}

\author{
Grant W.G. Cochrane \\ Department of Archaeology, The University of Sydney, NSW 2006, Australia \\ gcochrane1@iprimus.com.au
}

\begin{abstract}
An analysis of stone artefacts from the Arcadia Valley in south central Queensland is used to develop a core reduction sequence model for the region. During the initial construction of this model, core types are identified that reflect phases or end points in reduction trajectories. The model shows that core reduction methods employed in the Arcadia Valley during the mid-to-late Holocene included Levallois, discoidal, prismatic and burin blade core methods, along with less formal reduction strategies. In recognition of the equifinality of many reduction processes, the model has a flexible structure. Hence the prevalence of the various core reduction methods, and their relationships to each other, may be the subject of a range of hypothetical scenarios which can be tested by employing multiple lines of additional evidence. Following this procedure, it is concluded that Levallois and discoidal methods may account for close to half of the artefact assemblage, while less formal methods were also very common.
\end{abstract}

\section{Introduction}

Among the variety of questions that archaeologists explore through the analysis of stone artefacts are those which seek to understand how stone tools were manufactured in the past. There is a long history of this type of research, beginning in the nineteenth century but expanding significantly since the 1950s through the influence of experimenters such as Francois Bordes in Europe and Donald Crabtree in North America (Olausson 2010; Shott 2003; Tostevin 2011). The bulk of stone toolmaking in the past involved the reduction of a piece of stone by controlled percussion into a desired tool form, and so considerable research has been directed toward understanding the details of these reduction processes. The requirements of a particular tool may be very broad or very narrow, and so the degree of precision and planning that is necessary in the tool-making process will vary (Baumler 1995:19). Moore (2013:141) has suggested a dichotomy between 'simple' stone flaking, which involves contiguous chains of flake removals, and 'complex' stone flaking, which involves the strategic manipulation of mass through multiple flake removals in order to influence the shape of the core or the flakes struck from it. More commonly, Australian archaeologists have adopted the terms 'formal' and 'informal' to refer to relatively planned and relatively unplanned core reduction strategies.

The apparently high frequency of informal core reduction strategies is regarded by some as a notable characteristic of Aboriginal Australian lithic technology. Yet over the last few decades, archaeologists have documented a range of formal core reduction strategies that were employed in particular regions at various times in the past (e.g. Akerman 1976, 2007; Akerman et al. 2002; Clarkson 2007; Cochrane 2013; Cundy 1977; Doelman and Cochrane in press; Hiscock 1993; Luebbers 1978; Moore 2000a, 2000b, 2003a, 2003b, 2004, 2010; Newman and Moore 2013; Witter 1988, 1992). These studies demonstrate the variability in Aboriginal approaches to lithic reduction. The continued recording of this regional and temporal variability is important because it is germane to the development and testing of hypotheses about, for example, cultural change, social interaction, economic decision-making and the effect of raw material constraints (Moore 2013; Newman and Moore 2013).

It is equally important to avoid making narrow assumptions about why particular core reduction methods were employed. As Holdaway and Douglass (2012) recently observed in their review of the ethnography of Aboriginal approaches to stone tool manufacture and use, our typological systems do not necessarily reflect the values of the people using the tools. Core reduction sequences may seem to be directed toward production of particular types of flakes, but in fact the useful products often span beyond these flakes and can sometimes include most of the fractured material generated during knapping.

In this paper, I characterise core reduction sequences in the Arcadia Valley in south central Queensland. The primary objective is to document the processes involved while limiting any assumptions made about the intentions of the tool-makers. The consideration of other theoretical constraints on core reduction sequence modelling, such as time averaging of lithic assemblages and the equifinality of certain technological processes (Hiscock and Clarkson 2000:99-100), is also an important feature of this study.

\section{Study Area}

The Arcadia Valley ( 250-400m asl) forms the southernmost extreme of the Bowen Basin. It is enclosed to the west and south by the Carnarvon Range ( 600 $1200 \mathrm{~m}$ asl) and to the east by the Expedition Range ( 400-750m asl) (Figures 1-2). It owes its low relief to erosion of the friable Triassic Rewan Formation sediments that form the crest of the Arcadia Anticline. Around the margins of the valley the overlying, more resistant Jurassic Clematis Sandstone is preserved, and in these areas the landscape is more steeply dissected. The surrounding ranges consist of uplifted Mesozoic sandstones which have been capped in some places by Tertiary basalt flows. Seepage and stream erosion has deeply dissected the tableland, forming steep scarps and gorges within the ranges (Finlayson and Kenyon 2007; Young and Wray 2000). 


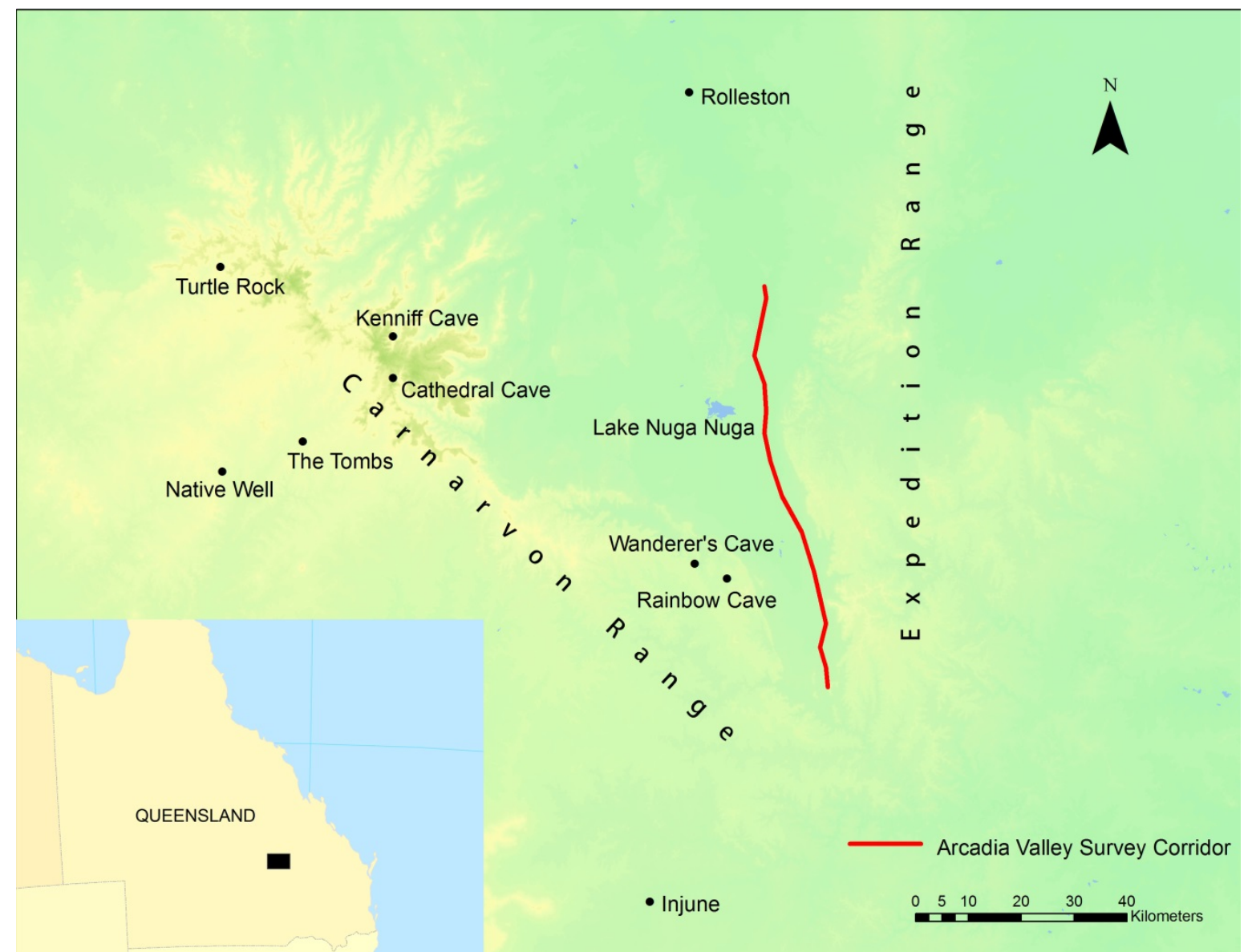

Figure 1. Location of the Arcadia Valley survey corridor and other sites mentioned in the text.

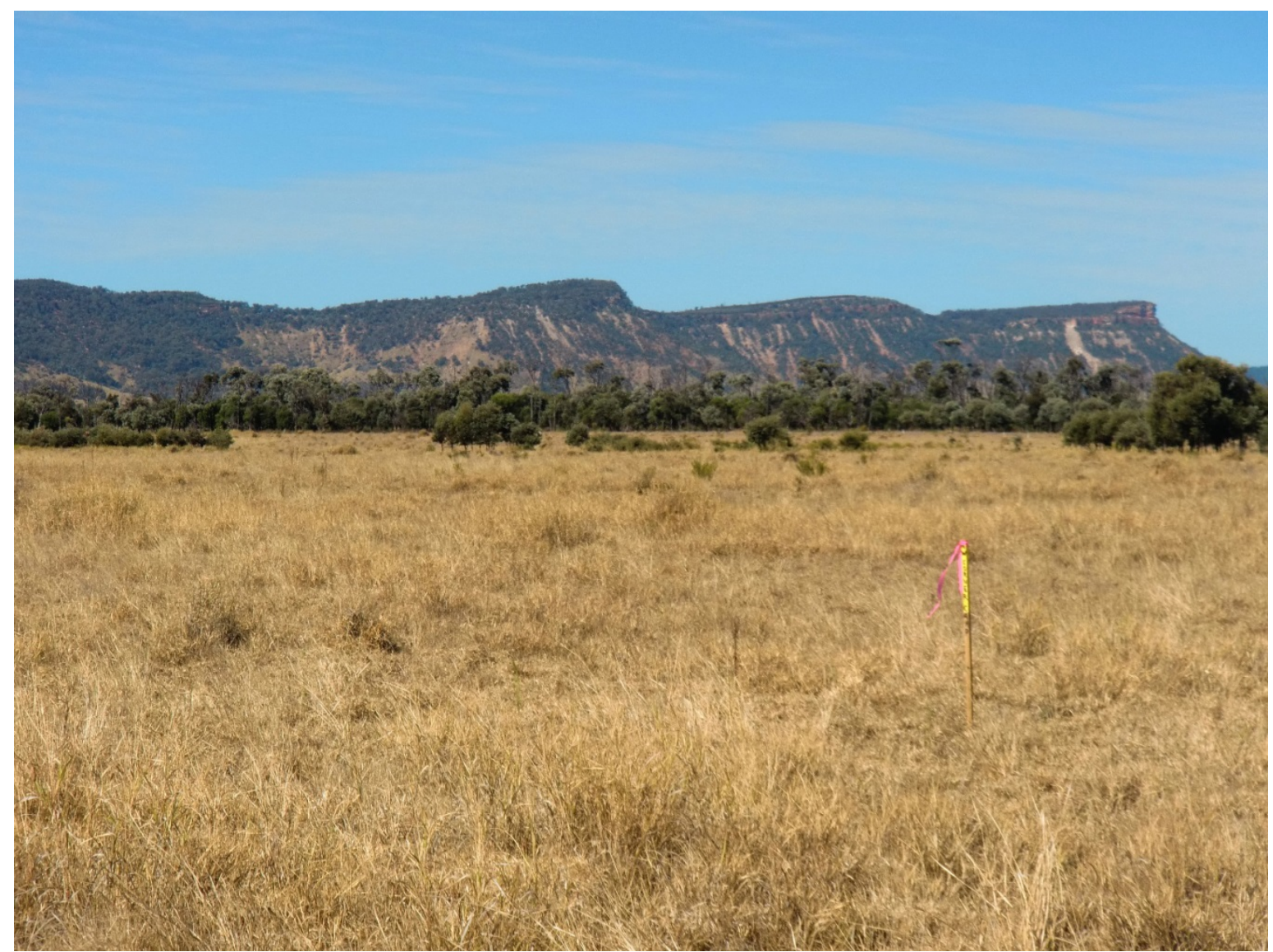

Figure 2. Part of the Arcadia Valley survey corridor, with the Expedition Range in the background (Photograph: Phillip Habgood). 
The best known archaeological sites of the region are found in the highlands. They include a number of rockshelters in the Carnarvon and Chesterton Ranges that together have been used to develop a three-phase regional chronology known as the 'central Queensland highlands cultural sequence' (Morwood 1984). Sites that were used to develop this cultural sequence include Kenniff Cave, The Tombs, Cathedral Cave, Rainbow Cave, Wanderer's Cave, Native Well 1, Native Well 2, Turtle Rock and Ken’s Cave (Beaton 1977, 1991a, 1991b; Morwood 1981; Mulvaney and Joyce 1965) (Figure 1). Vast numbers of Aboriginal archaeological sites, especially open site stone artefact scatters, have been identified and recorded in the lowland basins of south central Queensland in the course of cultural heritage management surveys over the last two decades. However, they have generated very little published lithic research (L’Oste Brown et al. 1998).

In 2010 an archaeological survey of a proposed pipeline corridor which ran most of the length of the Arcadia Valley was conducted (Figure 1). The corridor was $100 \mathrm{~m}$ wide and approximately $75 \mathrm{~km}$ long. Despite generally low levels of ground surface visibility, a large number of stone artefact sites were identified during the survey, including 25 significant Aboriginal areas (ARCHAEO 2010). In order to mitigate the disturbance of these sites during pipeline construction, a total of 5095 stone artefacts were collected and subjected to detailed analysis (ARCHAEO 2011; Cochrane 2011; Cochrane et al. 2012a, 2012b).

Our ability to date these stone artefact sites is currently very limited. Some of the retouched stone artefacts, such as backed artefacts, pirri points and thumbnail scrapers, are diagnostic characteristics of the Small Tool Industry ( 4300-2000 BP) of the central Queensland highlands cultural sequence, and so we can be confident that at least some of the artefacts were manufactured during this period. However, even artefacts found in close spatial proximity to these time-sensitive tools may have a completely different depositional history. The industries that precede and follow the Small Tool Industry are not defined by artefact forms that are exclusive to a single industry (with the exception of Juan knives in the Recent Industry), but rather by the absence of certain artefact types, and by comparative artefact deposition rates. As such they are of very limited value in helping to date open sites. However, the Arcadia Valley has a predominantly depositional geomorphological environment. Many of the minor channels that drain the highlands into the valley do not connect to a major channel but instead terminate their flow on the valley floor, where they deposit fans of sediment. Because of this, the courses of the valley's channels have changed quite abruptly at different points in the past, including relatively recent times (Finlayson and Kenyon 2007). Post-European land-use of the valley has mainly been limited to cattle grazing, and while this has resulted in an extreme change in the vegetation regime it has not led to widespread soil erosion. In these circumstances, it would be surprising if significant numbers of stone artefacts currently found on the ground surface were to date to the Pleistocene or early Holocene. It is far more likely that the majority of the artefacts collected during the mitigation programme were discarded in the mid-to-late Holocene.
Over $93 \%$ of the flaked stone artefacts in the Arcadia Valley assemblage were manufactured from silcrete, and the remainder from a broad variety of lithic materials including petrified wood, quartz, chert, quartzite and chalcedony. Cortical artefacts almost invariably bore smooth waterworn cortex consistent with that found on stream cobbles. Sources of silcrete cobbles located on the margins of the Arcadia Valley include the Dawson River, Carnarvon Creek, Clemaitis Creek, and palaeochannel floaters located near Carnarvon and Clemaitis Creeks. No silcrete cobble sources are located in the core part of the valley (Cochrane 2013:121-122; Galloway 1967a:84, 1967b:75).

\section{Core Reduction Sequence Models}

A core reduction sequence model is a particular way of characterising how an assemblage of flaked stone tools is made. It is usually presented in the form of a flowchart showing various stages that a knapper follows, from the initial preparation of the core to the point of core discard. A reduction sequence may be directed toward a single product, or it may produce a variety of usable products at various points along the sequence. Some flaking products result from relatively standardised, ordered reduction sequences, and indeed in some cases it would be very difficult to generate the product without following the rules of the sequence. Such products have their own staged pathway, or trajectory. Reduction strategies may be quite flexible and switch from one trajectory to another. Such switches are referred to as cross-overs (Moore 2003a:24-25).

Any model is by definition a simplification of reality. Concepts that are used in reduction sequence models, such as trajectories and desired products, imply clear goals, shared design templates and rigid adherence to rules. They also tend to be expressed in synchronic terms, which is generally discordant with the time-averaged nature of most archaeological assemblages. Thus when reduction sequence models are interpreted literally, they are vulnerable to criticisms of idealism and reductionism. It is incumbent on the authors of such models to be very conscious of semantics and, where possible, to express elements of their models in probabilistic terms.

There are also quite a few conditions that need to be met before reduction sequence modelling is viable. To obtain sufficient evidence, authors choose from a number of different methods. These include refitting of artefacts to retrace the reduction stages (Hiscock 1993; Luebbers 1978:221-223; Moore 2000a:28, 2003b:22-24; Witter 1988), detailed analysis of flake scar patterns (Chazan 2001:18; Hiscock 1993; Moore 2003b:22-24; Sellet 1993:108), experimental replication (Akerman 1976; Akerman et al. 2002; Moore 2000a:28, 2000b:57), metric analysis (Witter 1988), employment of a technological typology (Moore 2000a:28), ethnographic observation (Akerman et al. 2002) and historical research (Moore 2000b:57). All of these methods are very time consuming and most require a high level of expertise. Even if the resources are available, many archaeological assemblages will be unsuitable because they are too small or too biased. 


\section{The Arcadia Valley Core Reduction Sequence Model}

Originally, it was not anticipated that the construction of an integrated reduction sequence model would be possible within the scope of the Arcadia Valley stone artefact study. It was expected that some of the data categories, particularly those relating to core types and debitage attributes, would provide sufficient information to develop or test hypotheses about how some of the stone implements were made. Expectations began to change during the process of analysis and data recording when it became apparent that very distinctive Levallois and discoidal cores were present in the assemblage and that much of the debitage reflected a substantial amount of centripetal flaking. These are unusual characteristics in Australian stone tool assemblages and so it became necessary to revise the systematics employed in the study to ensure that these unexpected features could be fully understood.

The revisions mainly affected core and flake classification systems. The cores in particular provided a major source of evidence about the reduction sequences. For the purposes of this study, cores are defined as flaked artefacts that exhibit at least one striking platform and negative flake scars. The size and orientation of the flake scars are not consistent with edge retouch or resharpening but instead indicate that the artefact was used for the production of flakes. In raw numbers there were 401 cores, which was $7.9 \%$ of the total assemblage. A further 53 artefacts were classified as core fragments. The analysis of cores was aided by the use of a core typology.

Cores may be discarded at various points in a reduction sequence. They may take forms that are highly indicative of a particular reduction method or they may take forms that reveal very little. Therefore a core typology will usually consist of classes that vary in the quality of evidence that they provide about reduction strategies (Holdaway and Stern 2004:194). Because of this, a core typology is best regarded as a heuristic device rather than a strict taxonomic scheme. The core types employed in this study are based on clusters of attributes that are indicative of reduction methods. They are mutually exclusive but they do not necessarily reflect discontinuous variation (Shott et al. 2011). Instead they are interpreted as representing typical phases or end points in reduction continuums.

\section{Levallois and Discoidal Concepts}

The Levallois concept is used to describe a particular set of core preparation and flake production strategies that were prevalent in parts of Eurasia and Africa between 300,000 BP and 30,000 BP, but which have also been identified in a variety of other geographical and temporal contexts (e.g. Ballin 2012; Boëda et al. 2013; Dortch and Bordes 1977; Lycett and Norton 2010:60-61; Miller 1982; Otte 1995). These strategies have had the benefit of many decades of exposure and study and in consequence the concept of Levallois has undergone two important phases. Though originally described in the nineteenth century, it was some time later that Bordes (1950) argued that the significance of Levallois was that it involved core preparation as a means to a predetermined end product of a standardised shape. Through flint-knapping replications Bordes was able to identify typical Levallois products and, critically, this enabled the concept to be incorporated within typological systems (Schlanger 1996:223).

This fostered a period where Levallois was freely inferred from the typological characteristics of assemblages. It gradually became apparent though, that artefacts meeting the typological criteria of Levallois products, such as Levallois flakes and Levallois points, could be produced through non-Levallois techniques (Bar-Yosef and Dibble 1995:xi; Boëda 1995:43-45). This highlighted the fact that while there was a general appreciation that Levallois reflected a process, the process itself was not well understood. This problem began to be addressed in earnest by European lithic researchers in the 1980s, culminating in Boëda's (1995) characterisation of Levallois as a volumetric concept. The key to this concept was that the tool-maker was not guided by a prescriptive set of compulsory steps, but rather by some fundamental principles that distinguished Levallois from other forms of core reduction.

The first of these principles requires that the core be prepared in such a way that it consists of two opposed, convex, asymmetrical surfaces. Each of these surfaces has a specific role and those roles are fixed throughout the reduction sequence. The surface de débitage (or striking surface) is effectively the core face and the surface des plans de frappe (or striking platform) is the opposed surface.

The second principle is that two main types of flakes are struck from a Levallois core - predetermining and predetermined. Predetermining flakes are those which remove material from the striking surface so that a set of guiding ridges and localised convexities remain. The convexities are referred to as lateral and distal convexities, and they are frequently monitored and adjusted to ensure that the overall desired convexity of the striking surface is maintained. Predetermined flakes (or points or blades) are those which are struck once a suitable striking surface has been prepared, and have their standardised shape predetermined by the topography of the striking surface. The fracture planes of predetermined flakes are always oriented parallel to the plane that defines the two intersecting convex surfaces of the core.

The third principle is that the line formed by the intersection of the striking platform and the striking surface at the point where a predetermined flake is to be detached (the hinge) must be oriented perpendicular to the flaking axis of the predetermined flake. Detachment of the flake must be through hard hammer non-marginal direct percussion, with the impact of the blow landing on the striking platform a few millimeters from the hinge.

This definition provided a much more satisfactory explanation of what Levallois technology was but it also confirmed that Levallois debitage products could not always be identified purely through use of a typological system (Boëda 1995:45; Bar-Yosef and Dibble 1995; Meignen 1995:363-364; Sellet 1995:26; Shott 2003:100). The stereotypical Levallois flake - plano-convex in section, symmetrical in plan, with centripetal dorsal flake scars and a facetted platform - was characterised by a set of common but non-obligatory features. While having control over the point of impact was very important, facetting of the platform was not essential if the correct platform angle could be achieved by other means 
(Schlanger 1996:237). Likewise, the lateral and distal convexities did not necessarily have to be shaped by radial flaking if suitable surfaces already existed (Clarkson et al. 2012:170-171; Delagnes 1995:207; Meignen 1995:363). The failure of a flake to detach precisely as intended could have several causes, from knapping error to raw material defects (Dibble 1995:102; Ohnuma 1995). Thus the recognition of Levallois has become increasingly a matter of study at the assemblage level, rather than on an artefact by artefact basis (Van Peer 1995:8).

One of the main implications of the volumetric concept is that within Boëda's constraining principles there is scope for substantial technological variation (Delagnes 1995; Meignen 1995:361-362). One example of this variation is the dichotomy between preferential Levallois (the production of a single predetermined flake) and recurrent Levallois (the production of several predetermined flakes). Another is the distinction between different Levallois products - flakes, points or blades and the different initialisation processes required to configure the striking surface with suitable local convexities and ridges. A more complex form of variation, referred to as conjectural methods, involves the exploitation by a knapper of unexpected contingencies. In detailed refitting analysis of a Levallois core, Schlanger (1996) provided an example of this process in action. The detachment of a predetermined Levallois flake adventitiously left a striking surface suitable for detachment of a second predetermined flake without further preparation. Such a situation could not have been planned and instead reflects the status of Levallois as a flexible application of principles rather than rigid adherence to a fixed blueprint.

Another suggestion which has emerged since the development of the volumetric concept is that the traditional interpretation of predetermined flakes - that they were the intended product of the method - may not always be correct. Striking a large predetermined flake in a reduction sequence usually has the effect of flattening the core face and reducing the convexity of the surface. This acts as a counterpoint to predetermining flakes, which tend to promote convexity. The overall effect is that core face convexity tends to be maintained within a limited range, enabling reduction to continue without dramatic changes to platform angles or the nature of the flaking surface. Thus it is argued that, in some circumstances, the striking of predetermined flakes may be a form of core maintenance (Davidson and Noble 1993:376; Sandgathe 2004). There is evidence that, in some contexts, predetermining flakes were not simply regarded as knapping waste, but were chosen for use as implements. There is also evidence that the final flake removals on many Levallois cores were predetermining rather than predetermined flakes (Sandgathe 2004:150152). Both of these factors tend to support the notion that the Levallois concept was sometimes employed to promote continuous reduction sequences aimed at producing a large number of usable flakes (Dibble 1989). Aspects of this evidence can be contested, particularly because methods of identifying predetermining flakes are problematic (Wallace 2006). Yet the theory remains entirely plausible, at least in some contexts. Importantly, this alternative interpretation of Levallois reduction is built upon an understanding of the volumetric concept. It is not a challenge to the concept, or the notion that it underlies patterned core reduction. It merely expands the range of possible explanations for why people chose to employ Levallois methods. It also helps to emphasise that the terms 'predetermined' and 'predetermining' are primarily designed to distinguish between flake types based on their relationship to the geometry of the core, and need not be interpreted literally.

There has been considerable debate in the past about the relationship between Levallois and discoidal techniques and some workers have seen very little distinction between the two (Lenoir and Turq 1995; Ohnuma 1995). Boëda (1995:61-63) has outlined a volumetric conception for discoidal flaking and in so doing has highlighted the similarities and differences between Levallois and discoidal approaches. In both Levallois and discoidal conceptions the core consists of two convex asymmetrical surfaces that meet at a plane of intersection. However, unlike Levallois, in discoidal flaking the role of these two surfaces is interchangeable. Thus a surface can at one point form a striking platform and then later in the sequence form a striking surface. The maintenance of striking surfaces in both Levallois and discoidal conceptions is conducted to influence the size and shape of predetermined products but in the discoidal conception the convexities are maintained around the entire periphery rather than the localised lateral and distal regions. The fracture plane of both predetermining and predetermined flakes in the discoidal conception is oblique to the plane of intersection between the two surfaces, while the fracture plane of predetermined Levallois flakes must be parallel to the intersection plane. As a consequence of these distinctions, predetermined Levallois flakes tend to remove much of the established convexity from the striking surface and usually reestablishment of the convexities is required if another predetermined flake is to be detached. By comparison, the detachment of predetermined discoidal flakes will often have minimal effect on the general convexity of the striking surface and so the detachment of predetermined flakes tends to be a more continuous process.

There have been few previous claims made for the presence of Levallois technology in Australia. The term was thrown around loosely in some early attempts at classification (e.g. Horne 1921; McCarthy 1964:240) but the most detailed and convincing descriptions have come from Dortch and Bordes's (1977; Dortch 1972, 1977) analysis of Western Australian lithic assemblages, particularly from the Kimberley region, and Moore's (2003a) study of lithic artefacts from Camooweal in northwest Queensland.

The evidence from the Kimberley region comes from several sites in the Ord Valley. Levallois point, blade and flake cores and associated Levallois debitage have been described from these sites in 'Late Phase' assemblages that span the last 3000 years, including the recent European contact period. The Levallois artefacts cooccurred with products of other reduction methods, including discoidal and prismatic methods. In some respects they departed from stereotypical ideals. Plain platforms were more common than facetted platforms on the Levallois points, and many Levallois points and flakes were quite small in size, having been manufactured from 
small pebble cores. While there were good examples of artefacts that fit the various Levallois typological categories, Dortch (1977:117) acknowledged the problems of equifinality of techniques. Yet he also demonstrated through refitting that typical Levallois cores were flaked after the preferential flake had been detached, obscuring their Levallois status. These factors made it difficult to be precise about the contribution of Levallois technology to the industry (Dortch 1977:117-119). It appeared, for example, that many Levallois flake cores were subsequently converted into discoidal cores, which were themselves a common feature of Late Phase industries. Early phase assemblages (c.18,000 BP to 3000 BP) contained some evidence of discoidal technology and this technique has been noted fairly broadly across Western Australian sites. In contrast, Levallois appears to be restricted to the Late Phase in the Kimberley and possibly the Pilbara and Murchison districts of Western Australia (Bordes et al. 1983; Dortch 1977:123-125).

Moore (2003a) identified the production of Levallois points (which he termed 'blades') as one of five distinct reduction trajectories that characterised core reduction sequences at Camooweal in northwest Queensland. Moore's methods included flake scar analysis of cores and debitage, and knapping experiments to test the feasibility of reconstructions. Moore described three distinct Levallois reduction methods. The first two of these methods correspond to preferential and recurrent unipolar techniques. The third, the Camooweal Shark's Tooth Method, involved isolation of the platform so that the detached preferential point had a distinctive shark's tooth shape. A large proportion of the assemblage could be attributed to the Levallois reduction trajectory; there were 550 Levallois cores and 6765 Levallois points (or blades in Moore's terminology). Most of the points were between $30 \mathrm{~mm}$ and $90 \mathrm{~mm}$ long, which indicates that they were larger and more variable in size than Levallois points from northwest Australia. Moore (University of New England, pers. comm., 2011) has noted the possibility that Levallois technology could be more varied and more widespread in northwest Queensland but that much depends on the systematics being applied. The Camooweal assemblage was not dated.

This discussion of the Levallois concept has highlighted the fact that since its inception, Levallois has become increasingly recognised as a set of principles that guide a technological process rather than merely a descriptive term for stone artefacts. The stone artefacts are the static evidence and the existence of Levallois in the past must be inferred from that evidence, using middle range theory and the best analytical methods that are available. Equifinality of processes, the tendency for discarded cores to reflect only the latest phases of reduction, and the conflation of industries in surface assemblages are all potential problems that the archaeologist must confront (Dibble 1995). The core types set out in the following section include some types that were suspected to reflect stages of Levallois or discoidal technology. They will provide an important starting point for our assessment of the contribution of these technologies to the assemblage, and should not be taken to imply that I support a purely typological approach to such questions.

\section{Core Types \\ Test Cores}

Test cores are cores that have only had two or three random flakes struck from them before being abandoned. They usually occur on cobbles and may reflect the testing of the flaking qualities of material to find out if it is suitable for extensive flaking (Shiner et al. 2007:39).

\section{Bipolar Cores}

Bipolar cores are usually small cobbles or pebbles that display evidence that they have been used for the production of flakes by bipolar (or anvil rested) percussion. Evidence of bipolar percussion may include a flake scar of a wedging fracture, or crushing at both platform and distal ends. Quartz tends to be a common rock type for bipolar flaking because it is not very amenable to hertzian fracture (Holdaway and Stern 2004:196).

\section{Horsehoof Cores}

The horsehoof core is a distinctive Australian core type which has been a feature of numerous Pleistocene and early Holocene assemblages. It also occurs in more recent contexts (Kamminga 1982:85). Horsehoof cores have a single platform with flakes struck all around its perimeter. Continuous flaking of the core faces occurs until the platform angles become very steep. The final flakes struck from these steep platform angles are smaller and step or hinge terminated, and the resulting flake scars undercut some or all of the platform. When the core is discarded it is therefore high-domed and has a characteristic horsehoof shape.

\section{Conical Cores}

Conical cores have either a single platform and a clearly defined base, or two platforms at opposed ends. Flakes and/or blades are struck around most or all of the perimeter. Platform angles are generally quite steep which helps to maintain the conical shape. Distal core maintenance is often necessary in single platform types. Conical cores as defined for this study have relatively long core faces; as a rule of thumb the length of the core face is greater than the diameter of the platform. The variability described above implies four possible subtypes: single platform flake or blade cores and double platform flake or blade cores.

\section{Pyramidal Cores}

Like single platform conical cores, pyramidal cores have flakes and/or blades struck around most or all of the perimeter of a single platform. As defined here they are also longer from platform to base than the length of the platform diameter. The difference is that instead of having a flat base, the flake scars converge at the base to form a pyramidal shape. Both conical and pyramidal cores are usually the product of a formal reduction sequence which aims to maximise the usable mass of the core. This is sometimes referred to as prismatic core technology. On some occasions they may reflect different stages of the same reduction sequence (Holdaway and Stern 2004:194195); for example the flat base of a conical core may be transformed into a convergent one by removal of flakes with plunging terminations. 


\section{Burin Blade Cores}

Burin blade cores are a special form of blade core manufactured on flake blanks. One margin of a flake is usually retouched to form a platform, and an adjacent margin of the flake forms a narrow core face with a sharp ridge, which guides the propagation of the first blade. Successive blades are then struck, using scars from previous blade removals as guiding ridges. Blades may then be struck from other margins of the flake blank. The method is generally associated with the Small Tool Tradition of the mid-to-late Holocene (Cochrane 2013; Cundy 1977; Hiscock 1993; Luebbers 1978:223-225; Moore 2000a; Witter 1992:50).

\section{Single Platform Flat Cores (SPFC)}

These cores have a single platform with flakes struck around most or all of the perimeter. They differ from pyramidal and conical cores in that the length of the core from platform to base is smaller than the diameter of the platform. Within this category, two separate subtypes are distinguished. SPFC (Invasive) are cores where some or all of the flake scars are invasive, and SPFC (Steep) are cores where all flake scars are non-invasive. In some classification schemes, some or all of these cores would be classed as scrapers. Here they are distinguished from scrapers because the flake scars are large relative to the available flaking surface.

\section{Discoidal Cores}

Discoidal cores are defined by their concordance with Böeda's discoidal volumetric conception. They consist of two convex asymmetrical surfaces, the intersection of which defines a plane of intersection. The fracture plane of all flake scars is at an oblique angle to the plane of intersection of the two surfaces. The flake scars originate from striking platforms at the margin of the plane of intersection. The core may be unifacial but most frequently it is bifacial (Jaubert and Farizy 1995:229; Ohnuma 1995:257-258; Terradas 2003). Flake scars are centripetally directed and continuous.

\section{Levallois Cores}

Our ability to recognise core types that reflect a particular reduction method can depend greatly on the state of the cores when they were discarded. The reason why discoidal or prismatic cores are frequently discarded in a recognisable state is because once initialisation of the core has occurred, the process of flake detachment is relatively repetitive. Detached flakes are both predetermined and predetermining. Hence core maintenance activities have only minor effects on the overall core morphology. Only a complete switch in reduction strategy would be likely to remove the diagnostic elements of the core (Boëda et al. 2013; Terradas 2003:27).

In contrast, the complex nature of Levallois technology and the deleterious effects of Levallois core repreparation implies that the recognisability of a Levallois core will vary greatly, depending on the stage of reduction represented at the time of discard (Meignen 1995:363; Texier and Francisco-Ortega 1995:217; Tuffreau 1995:414), and the degree of success that the knapper has had in detaching a predetermined flake (Ohnuma 1995:263). If a Levallois core is discarded after the satisfactory detachment of a predetermined flake, then it should be relatively easy to determine whether it was flaked in accordance with the principles of the Levallois concept. On the other hand, if it is discarded after repeated attempts to reprepare the striking surface have been unsuccessful, or if the final predetermined flake was smaller than expected, there will be less evidence and more doubt. One could adopt a highly stringent definition omitting all but the most unequivocal cases from the class of Levallois core, but this would mean turning a blind eye to a large body of significant evidence. The approach taken here is to class cores as Levallois if it can be reasonably inferred that they were a product of Levallois technology; that is

- the core consists of two opposed, convex, asymmetrical surfaces that meet at a plane of intersection;

- one (and only one) of these surfaces can be recognised as the striking surface, bearing the scars of at least one predetermined flake, which is oriented parallel to the plane of intersection;

- there must be evidence that the shape of predetermined flakes has been determined by lateral and distal convexities of the core at the time of their detachment; and

- $\quad$ the hinge of a predetermined flake must be oriented perpendicular to its flaking axis.

\section{Core Rotation Categories}

It was anticipated that a large number of cores would not fit into any of the above categories. For these cases four additional categories were established based on the extent of core rotation. To ensure that all core types in the system were mutually exclusive, these core rotation categories were only employed in default of any other category being applicable. They reflect the extent of core rotation and are based on the number of platforms that were utilised. Defining what constitutes a platform on a core can be very difficult. As a core is reduced, prior platforms can be removed by subsequent flaking. Also, in this assemblage it was apparent that there was a lot of centripetal flaking emanating from a single platform, even though flakes are oriented in all directions. It was therefore necessary to consider not only the orientation of flake scars but also whether the core could be divided into discrete core faces before estimating the number of platforms that were employed. The four core rotation categories were defined as follows.

\section{Single Platform Cores}

Single platform cores are cores with flakes struck from only one platform. They do not meet all of the technological criteria of conical, pyramidal, horsehoof or single platform flat cores but many cases would be consistent with early phase reduction stages of each of these core types.

\section{Bifacial Cores}

Bifacial cores are cores with two adjacent faces that alternate as both core face and platform. Some bifacial cores are consistent with early phase reduction stages of discoidal cores. 


\section{Dual Platform Cores}

Dual platform cores are any other cores that have flakes struck from two discrete platforms.

\section{Multi-Platform Cores}

Multi-platform cores are cores with flakes struck from more than two platforms. These cores are highly variable. The morphology and flake scar orientation of some suggest that they were the product of relatively informal flaking methods. Others retain evidence of careful centripetal or bifacial flaking and may reflect attempts to exploit or rehabilitate failed Levallois or discoidal cores. Still others are heavily reduced and retain little technological evidence at all.

\section{From Core Typology to a Reduction Sequence Model}

Table 1 provides a summary of the Arcadia Valley cores classified according to core type. Of the 38 cores classed as Levallois (Figure 3a-h), 19 were discarded after detachment of a predetermined flake, 17 were discarded after detachment of predetermining flakes that were struck during a phase of repreparation, and two were discarded after breakage. The extent of repreparation prior to discard varied greatly. In some cases it involved just a few small flakes to reprepare a platform. In others major flaking had taken place to re-establish lateral and distal convexities.

The Arcadia Valley Levallois cores exhibit a great deal of variety. In recent times assessments of Levallois variability have tended to focus on the dichotomy between preferential and recurrent Levallois, and the different predetermined products (flakes, blades and points). Table 2 shows that in the Arcadia Valley, both preferential and recurrent methods were employed, and that flakes, blades and points were all manufactured by the Levallois method. Flakes appear to have been the most common targeted product and, at least on the evidence of these cores, were mostly produced using the preferential Levallois strategy. Point cores were much less numerous but follow the same pattern. Recurrent Levallois is more evident in the production of blades. All recurrent Levallois cores in the assemblage were unipolar.

Table 1 provides a breakdown of the characteristics of the Arcadia Valley cores at their point of discard. In isolation most of these core types are intrinsically reflective of particular reduction methods but it remained unclear whether there were relationships between these various reduction methods, or whether each core type was the end product of a discrete method. To investigate this question further, more detailed analysis was conducted of a sample of the cores. The sample consisted of 316 out of the 401 cores identified in the assemblage. These cores were subjected to flake scar analysis with two main aims. The first was to investigate in more detail the processes involved in early phase preparation of Levallois and discoidal cores. The second was to investigate regularities in the reduction sequences of the other core types with a view to identifying similarities and potential relationships between them. The analytical approach to flake scar analysis was essentially one of 'mental refitting' (Chazan 2001:18; Hiscock 1993; Moore 2003b:22-24; Sellet 1993:108), which involved closely examining the sequence of flake scar overlap on the cores.
Table 1. Classification of Arcadia Valley cores according to core type.

\begin{tabular}{|l|r|}
\hline \multicolumn{1}{|c|}{ Core Type } & Number \\
\hline Test Core & 2 \\
\hline Bipolar Core & 2 \\
\hline Horsehoof Core & 1 \\
\hline Single Platform Flake Conical Core & 6 \\
\hline Single Platform Blade Conical Core & 5 \\
\hline Double Platform Flake Conical Core & 1 \\
\hline Pyramidal Flake Core & 12 \\
\hline Pyramidal Blade Core & 4 \\
\hline Burin Blade Core & 5 \\
\hline Single Platform Flat (Invasive) Core & 24 \\
\hline Single Platform Flat (Steep) Core & 13 \\
\hline Discoidal Core & 36 \\
\hline Levallois Core & 38 \\
\hline Single Platform Core (Default) & 34 \\
\hline Bifacial Core (Default) & 39 \\
\hline Dual Platform Core (Default) & 21 \\
\hline Multi-Platform Core (Default) & 158 \\
\hline Total & 401 \\
\hline
\end{tabular}

Table 2. Classification of Arcadia Valley Levallois cores according to strategy (preferential versus recurrent) and predetermined flake type.

\begin{tabular}{|l|r|r|r|r|}
\hline & \multicolumn{1}{|c|}{ Flakes } & \multicolumn{1}{|c|}{ Blades } & \multicolumn{1}{c|}{ Points } & Total \\
\hline Preferential & 22 & 4 & 4 & 30 \\
\hline Recurrent & 2 & 6 & 0 & 8 \\
\hline Total & 24 & 10 & 4 & 38 \\
\hline
\end{tabular}

\section{Early Phase Preparation of Levallois and Discoidal Cores}

One aspect of variability in Levallois technology that is not discussed frequently relates to the steps taken to initialise the core so that it consists of two opposed convex surfaces, rather than an amorphous piece of rock (Delagnes 1995:207; Meignen 1995:364-365). Although the vast majority of Levallois cores were, like other Arcadia Valley flaked artefacts, manufactured on silcrete cobbles, there was an impression during initial data collection of great diversity in the application of the Levallois concept. It was hoped that flake scar analysis could reveal some regularities in the early phase preparation of Levallois cores. While the impression of diversity was a correct one, the analysis was able to discern three broad approaches to core initialisation (Figure 4).

\section{Blocking Out a Cobble}

Under this method a cobble is flaked roughly into a cube or block shape. Before the striking platform and striking surface are clearly defined, a combination of two or three faces are selected and small centripetal flakes are struck around their entire perimeter. After this phase, one or two faces will be defined as the striking surface, and if necessary longitudinal predetermining flakes are struck to better define the lateral margins. After this phase centripetal predetermining flakes are struck wherever it is necessary to promote the lateral and distal convexities. 


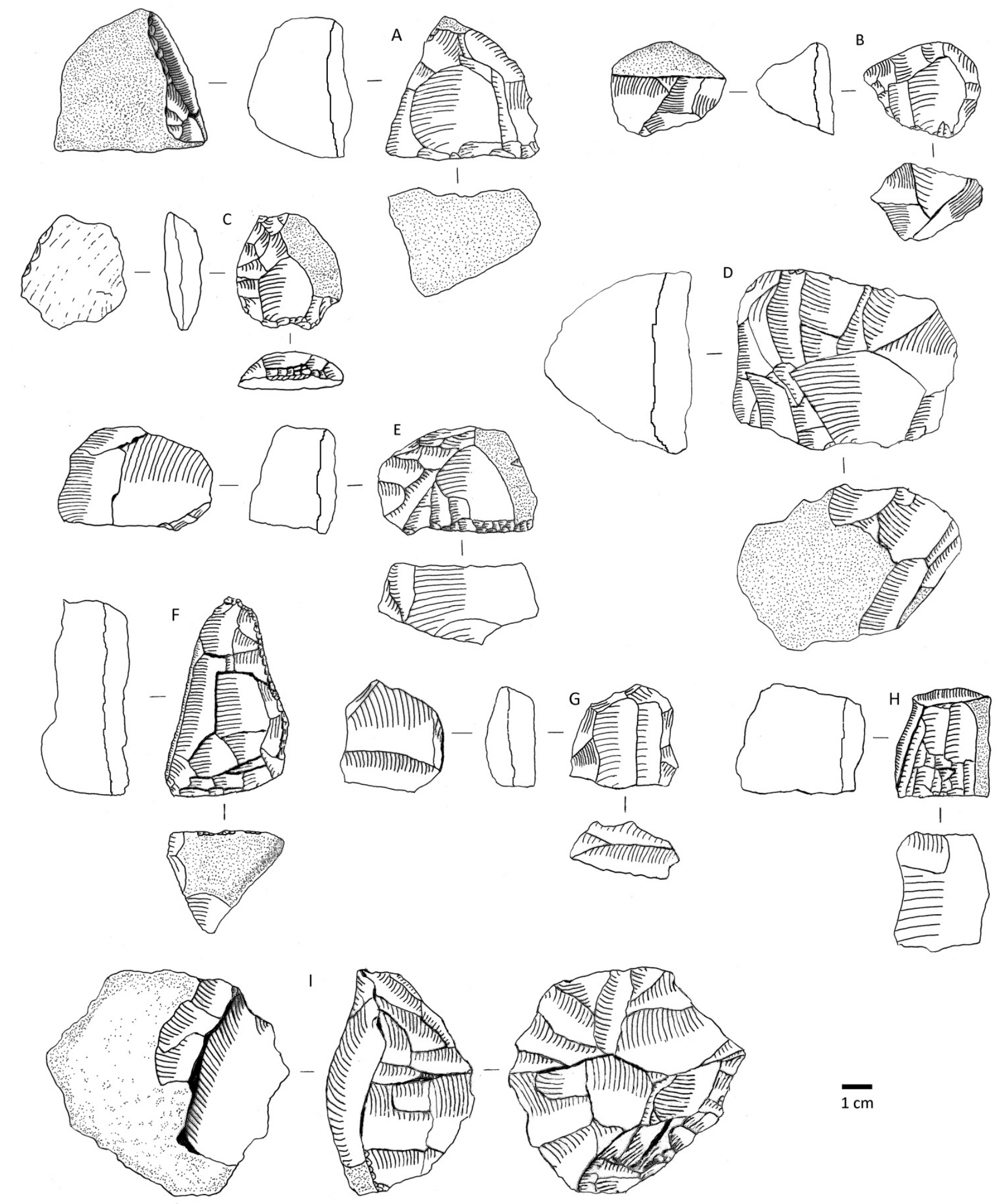

Figure 3. a-e: Levallois flake cores, f-h: Levallois blade cores, i: discoidal core. 


\section{Blocking out a cobble}
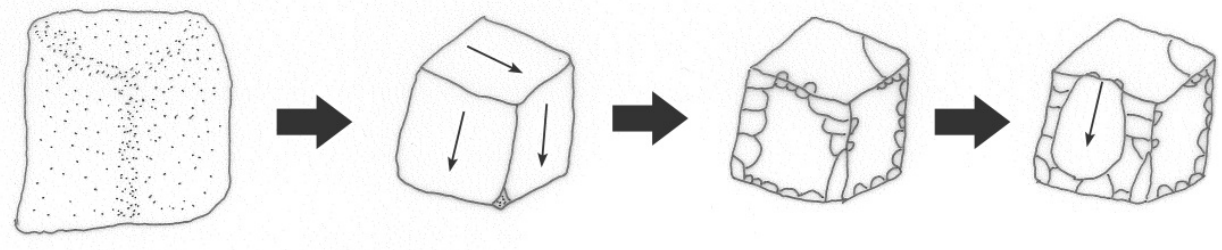

\section{Flake blank ventral surface as striking surface}
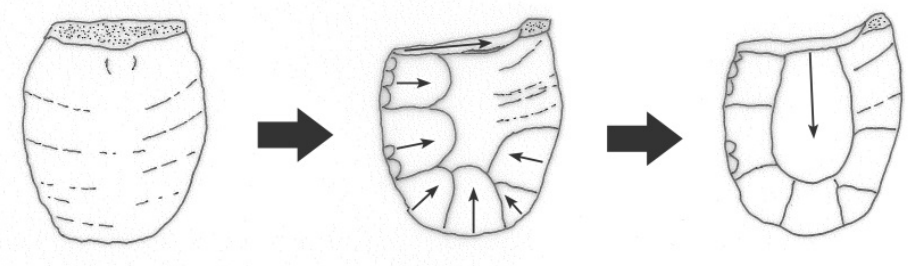

\section{Flake blank dorsal surface as striking surface}
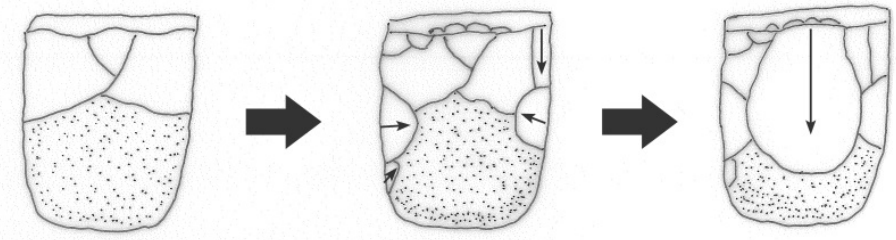

Figure 4. Three methods of Levallois core initialisation in the Arcadia Valley.

\section{Ventral Surface of a Flake Blank as Striking Surface} In its most basic form this method involves the striking of a suitable flake blank and the delineation of the ventral surface as the Levallois striking surface. Centripetal predetermining flakes are struck around the margin to promote lateral and distal convexities. The natural curvature of the bulb of percussion also contributes to the convex surface of the predetermined flake. Parts of the flake blank, especially the distal area, may be broken or steeply flaked to promote the convexity of the opposed striking platform surface. The predetermined flake may be struck from the striking platform of the original flake blank or a newly facetted platform.

Variants of this method include striking large flakes to create a ridge within the ventral surface which becomes a lateral margin of the striking surface, or combining the flake blank platform with the ventral surface to form the striking surface.

\section{Dorsal Surface of a Flake Blank as Striking Surface} This method is similar to the ventral method with the roles of the two sides of the flake blank reversed. It usually involves the striking of centripetal predetermining flakes around the margin of the dorsal surface to promote lateral and distal convexities. These convexities may also be promoted through the strategic utilisation of existing ridges or naturally curved cortical surfaces. The predetermined flake may be struck from the platform of the original flake blank or a new platform. Less commonly, the striking surface may be limited to only part of the dorsal surface of the flake blank, which is separated from the rest of the dorsal surface by a prominent ridge.

Most of the discoidal cores in the Arcadia Valley assemblage were manufactured on flake blanks but a few were made on cobbles (Figure 3i). Usually, flake blanks would be bifacially, centripetally flaked around most or all of the perimeter, with the ventral surface forming one convex face and the dorsal surface the other. The treatment of the flake blank platform varied. Sometimes it would be combined with either the ventral or dorsal surfaces to form one of the convex faces. On other occasions it would be flaked on both sides, or removed by flaking. In the case of unifacial discoidal cores manufactured on flake blanks, a convex dorsal surface or convex ventral plus platform surface served as a platform and centripetal flakes were struck into the opposing face.

The initial shaping process of discoidal cores made on cobbles is unclear but it appears that flat cobbles were preferred. In unifacial cases it appears that the cobble was originally split or broken and then centripetal flakes were struck from the cortex into the broken surface until two opposed convex surfaces were formed. Bifacial cases may be merely an extension of this process, where the platforms are switched and centripetal flakes are struck into the cortical surface.

\section{Relationships between Core Types}

Most of the observations that were made during flake scar analysis about the relationships between core types have been included in the foregoing discussions, but here a summary will be provided. Single platform cores, depending on their morphology, can be consistent with early preparation phases of conical cores, pyramidal cores, horsehoof cores or single platform flat cores. Single platform conical cores could, with further flaking, be transformed into pyramidal cores, horsehoof cores or double platform conical cores. Any single platform core could be converted into a bifacial core, and both bifacial and single platform flat cores have morphologies consistent with the initialisation phases of discoidal cores. All cores could, through changes in flaking trajectory, eventually be converted into multiplatform cores. The key to these observations, at this stage of discussion, is that all of these trajectories are hypothetical. They can provide us with the foundations of a reduction sequence model but the model must have sufficient flexibility to accommodate a range of possible reduction trajectories and cross-overs. 


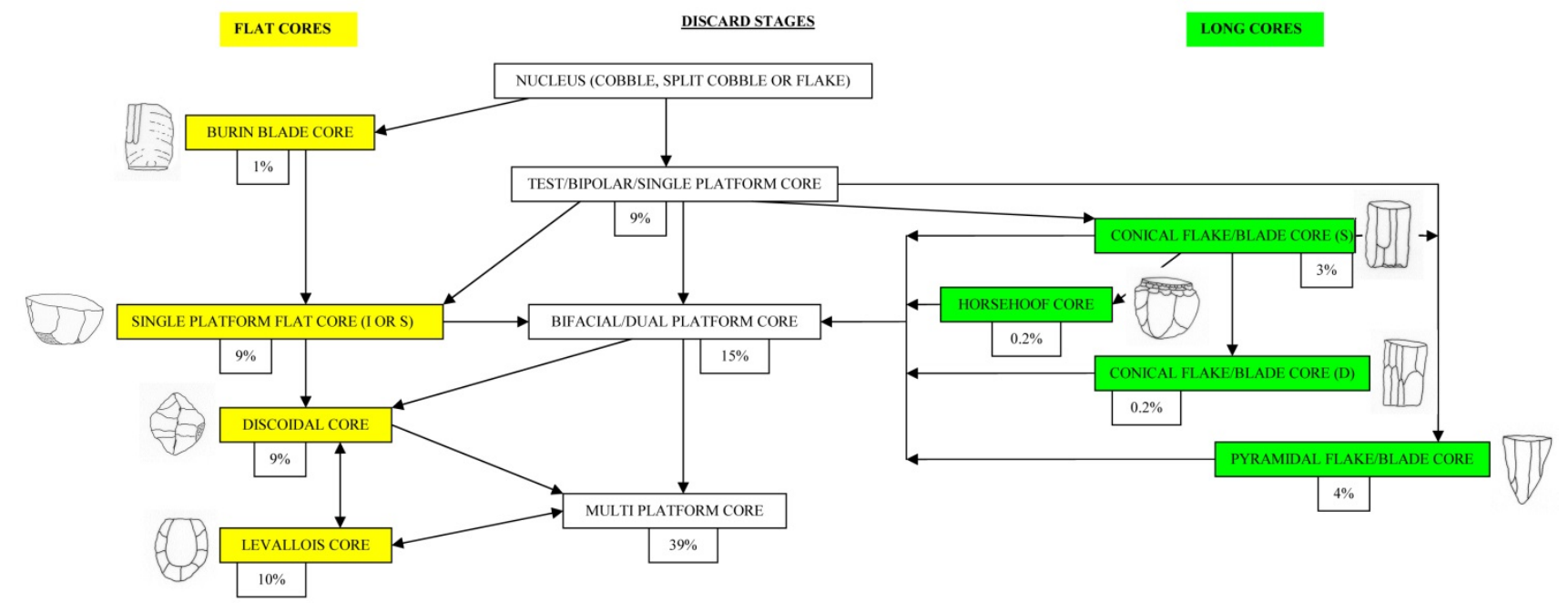

Figure 5. The Arcadia Valley reduction sequence model.

It must also be asked where Levallois fits into this model. The assessment of Levallois initialisation stages did not reveal a consistent approach to the preparation of Levallois cores. On the contrary, the employment of Levallois technology in the Arcadia Valley seems to have been highly flexible in nature. The unifying factor is the geometric concept.

Are any of the other core types consistent with early or late phases of Levallois production? The close relationship between discoidal and Levallois technology has been noted and the initialisation phase of Levallois cores, especially those produced on flakes, could be achieved through employment of the discoidal conception. The blocking out a cobble method discussed above would, through most of the initialisation process, resemble one of the default core rotation types, passing through single platform, dual platform and multiplatform stages before the two convex surfaces become well defined. The latter phases of Levallois core flaking could include failed attempts at repreparation leaving the appearance of a discoidal core or a cross-over to a less formal flaking method resulting in a multi-platform core.

\section{The Core Reduction Sequence Model}

The Arcadia Valley core reduction sequence model that has been inferred from the above evidence is represented as a flow chart in Figure 5. In this model, each of the core types is interpreted as a phase or end point of reduction. The arrows show potential trajectories and cross-overs between these phases. Cores on the left of the chart have been labelled 'flat cores' and cores on the right have been labelled 'long cores' in recognition of a general morphological distinction between the two groups. The potential for cross-overs between these two groups is limited. Long cores may be converted into discoidal or Levallois cores via the pathway of a bifacial, dual platform or multi-platform core, but there is no trajectory to transform a flat core into a long core.

The actual percentage representation of each core type in the assemblage is also shown in the chart. The flexibility of the model can be demonstrated by considering these percentages. Every core type in the assemblage was discarded for one of two reasons. Either the knapper had achieved their objective and the task was finished, or the knapper had failed to achieve their objective and the task was abandoned. In cases of the former, the reduction strategy pursued by the knapper may be reflected in the discard state of the core. In cases of the latter, the reduction strategy conceived by the knapper lies in one of the trajectories that flow beyond the discard state of the core (Baumler 1995:16-17; Dibble 1995:101-102). This presents a myriad of hypothetical possibilities within the one model. For example, at one extreme we could assume that the discard state of every core reflected the intended consequences of the knapper. If this were the case then each core type would be the end point of a discrete reduction strategy and the percentages shown next to each core type would be an accurate indication of the contribution of each of these strategies to the assemblage. To consider another extreme, single platform cores, bifacial cores, dual platform cores, multiplatform cores, single platform flat cores and discoidal cores could all be simply stages in the preparation of Levallois cores. Under this scenario, the cores discarded in these various states reflect the failure of the knapper to achieve their ultimate objective. In the first example, Levallois technology would account for $10 \%$ of the assemblage and in the second it would account for about $91 \%$ of the assemblage. Thus while the flexibility of the model is in some respects a virtue, it is clear that more information is needed to be able to assess the probabilities of different reduction scenarios.

\section{Assessing the Significance of Levallois and Discoidal Technology in the Arcadia Valley}

The analyses that led to the construction of the core reduction sequence model revealed that a variety of core reduction methods were utilised in the Arcadia Valley. In this section my focus is on gaining a more accurate assessment of the contribution of Levallois and discoidal methods. It is important to pursue this question because there is little prior evidence of the use of either method in the region, and in the case of Levallois its rarity extends to the continental scale. My approach consists of two separate analyses. The first involves some additional attribute analysis of a sample of cores and the second focuses on flakes. 


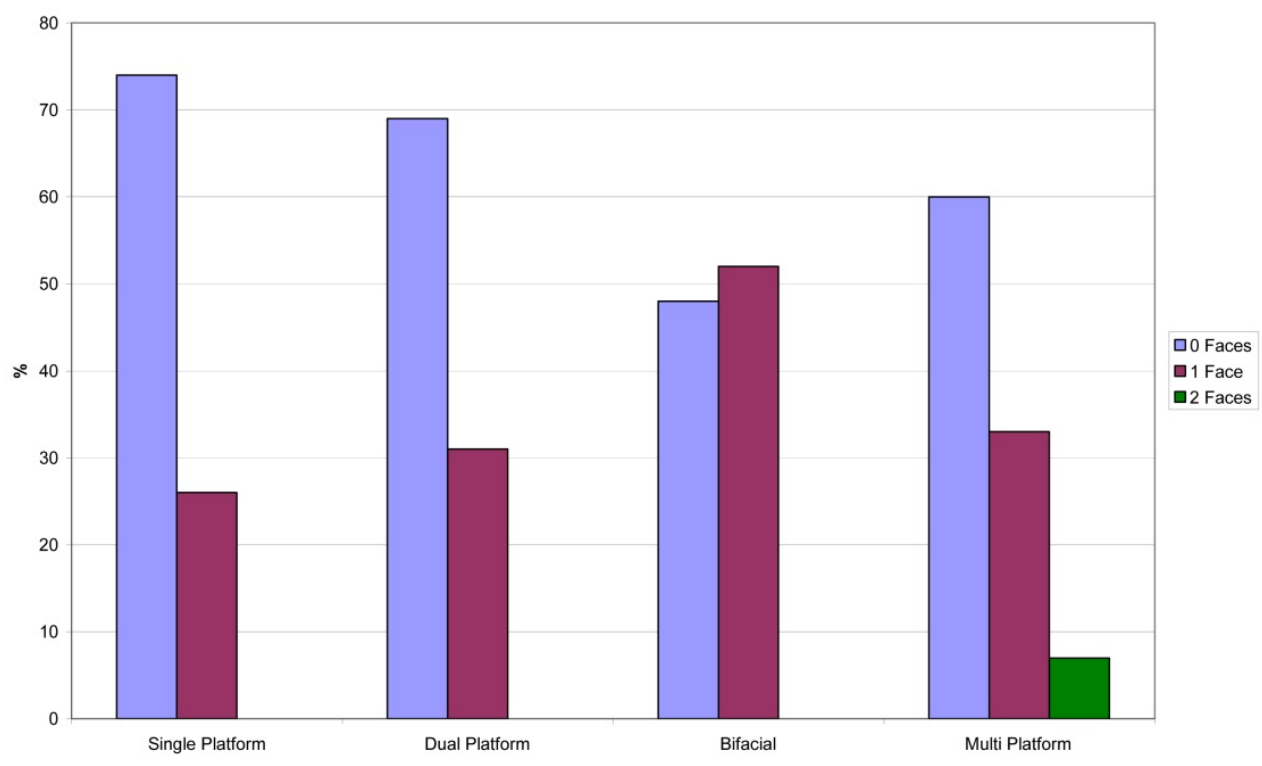

Figure 6. Percentage of core faces with at least $75 \%$ centripetal flaking, in the four default core categories.

\section{Further Analysis of Default Core Types}

As discussed above, four of the core types - single platform cores, bifacial cores, dual platform cores and multiplatform cores - were used to classify cores that bore little or no evidence of formal reduction strategies. This implies either (i) that these cores were not the subject of formal reduction strategies, or (ii) that they were at some point the subject of formal reduction strategies, but the latter stages of reduction had removed crucial evidence.

A feature that some of these cores had in common with Levallois and discoidal cores was the presence of centripetal flake scars around discrete core faces. This cannot on its own be used to infer that the core had a past or intended future Levallois trajectory, but given the dearth of other explanations for these features, it should be considered a strong possibility.

Using the sample of cores made available for flake scar analysis, the cores classed as single platform, bifacial, dual platform and multiplatform were reanalysed to determine whether they had core faces exhibiting centripetal flaking around at least $75 \%$ of their circumference. The results are shown in Figure 6. They indicate that centripetal flaking of core faces is a very common feature in the assemblage and it occurs frequently in core types that are otherwise undiagnostic of any particular flaking strategy. The centripetal flaking is usually only present on one core face, but on a few multiplatform cores it was observed on two core faces.

I interpret these results as supporting evidence for the argument that Levallois and discoidal methods were more prevalent in the valley than the raw data on core types might suggest. In addition to the $19 \%$ of cores that have been classed as Levallois or discoidal, 9\% have been classed as single platform flat cores which may reflect early phases of these strategies, and almost $25 \%$ have been classed in default core categories but bear features suggestive of past or intended future employment of Levallois or discoidal strategies. It is therefore not unreasonable to suggest that up to half of the stone flaking represented in the Arcadia Valley assemblage was guided by either Levallois or discoidal volumetric conceptions.
Table 3. Data categories employed to describe dorsal flake scar patterns.

\begin{tabular}{|l|l|}
\hline \multicolumn{1}{|c|}{ Category } & \multicolumn{1}{c|}{ Description } \\
\hline Unidirectional & No Dorsal Scars \\
\hline Lateral & $\begin{array}{l}\text { Dorsal scars emanating from the direction } \\
\text { of one lateral margin }\end{array}$ \\
\hline Oppositional & $\begin{array}{l}\text { Dorsal scars emanating from the direction } \\
\text { of the distal margin }\end{array}$ \\
\hline Bilateral & $\begin{array}{l}\text { Dorsal scars emanating from the direction } \\
\text { of both lateral margins }\end{array}$ \\
\hline Lateral-Distal & $\begin{array}{l}\text { Dorsal scars emanating from the direction } \\
\text { of one lateral margin and the distal margin }\end{array}$ \\
\hline Radial & $\begin{array}{l}\text { Dorsal scars emanating from the direction } \\
\text { of both lateral margins and the distal } \\
\text { margin }\end{array}$ \\
\hline
\end{tabular}

\section{Flake Analysis}

Like cores, the attributes of flakes can provide us with information about reduction strategies. The flake scars on dorsal surfaces may be particularly helpful in testing inferences made from core scars.

\section{Dorsal Flake Scar Orientation}

Summary data of the dorsal flake scar patterns on complete flakes (including retouched flakes) provide further evidence that core reduction in the Arcadia Valley frequently involved radial flaking of core faces. Excluding blades and flakes with indistinguishable flake scar patterns, six data categories were employed to describe dorsal flake scar patterns (Table 3). Dorsal flake scars emanating from the direction of the platform, while common, are regarded as redundant in this scheme because the flake itself emanates from that direction.

It is important to stress that flakes were only assigned to a particular category if the evidence of flake scar direction was clear. Where doubt existed, inferences tended to err on the side of fewer flake scar directions.

Table 4 shows the prevalence of each dorsal flake scar category. Figure 7 illustrates the same data, but with Lateral and Oppositional grouped together to represent flake scars from two directions and Bilateral and LateralDistal grouped together to represent flake scars from three directions. Unidirectional and Radial represent flake scars 


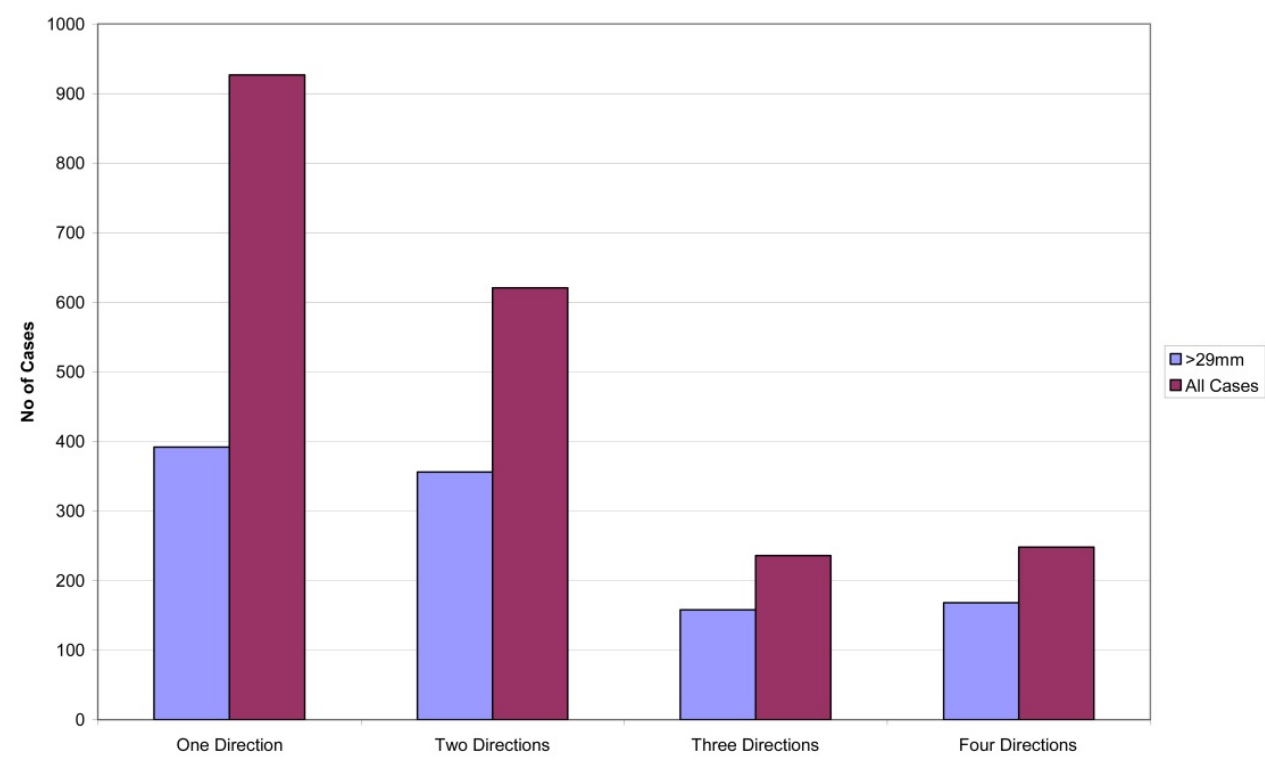

Figure 7. Dorsal flake scar orientation of unbroken flakes (including retouched flakes, excluding blades and indistinguishable cases).

from one direction and four directions respectively. These summaries indicate that core faces were frequently flaked from a variety of directions. Significantly, this evidence is strongest amongst the larger flakes. If the patterns were simply reflecting a lot of informal core rotation, it would be expected that the incidence of multidirectional flake scars would be more common in smaller flakes. I believe that these patterns instead confirm that a substantial amount of flaking in the Arcadia Valley followed the principles of Levallois technology.

This assertion is supported when we consider dorsal flake scar patterns from other Australian assemblages. In Hiscock's (1986) analysis of Hunter River valley assemblages he distinguished flakes that had dorsal flake scars emanating from either lateral or distal margins. These flakes made up less than $1 \%$ of Pre Bondaian assemblages, and less than $10 \%$ of Phase I and Phase II Bondaian assemblages. By comparison, they comprise over $54 \%$ of flakes in the Arcadia Valley assemblage.

\section{Termination}

Another revealing flake attribute to be considered here is flake termination. The ideal termination will depend upon the goal of a particular flake. Feather terminations, which taper slightly to meet the core face at a very acute angle, are often regarded as the product of accurate blows with an optimal amount and direction of force (Pelcin 1997:1107). However, abrupt terminations, which occur when a fracture path travels relatively undisturbed through a core and exits at a point at or near the base (Cotterell and Kamminga 1987:699-700), may also be optimal in some circumstances. The purpose of maintaining lateral and distal convexities on the striking surface of a Levallois core is to ensure that the dorsal surface of predetermined flakes is convex. This is best achieved if the fracture path is continuous and its exit point corresponds with the distal convexity. Thus an abrupt termination will often be a natural outcome of Levallois flaking.
Table 4. Classification of Arcadia Valley unbroken flakes (including retouched flakes) according to dorsal flake scar categories.

\begin{tabular}{|l|r|r|r|}
\hline & \multicolumn{2}{|c|}{ Maximum Dimension } & \\
\hline & $\mathbf{1 - 2 9 m m}$ & $\mathbf{7 9 9 m m}$ & Total \\
\hline Unidirectional & 535 & 392 & 927 \\
\hline Lateral & 128 & 210 & 338 \\
\hline Oppositional & 137 & 146 & 283 \\
\hline Bilateral & 21 & 56 & 77 \\
\hline Lateral-Distal & 57 & 102 & 159 \\
\hline Radial & 80 & 168 & 248 \\
\hline Total & 958 & 1074 & 2032 \\
\hline
\end{tabular}

Table 5. Frequency of termination types on unbroken flakes (including retouched flakes.

\begin{tabular}{|l|r|}
\hline \multicolumn{1}{|c|}{ Termination Type } & No. of Cases \\
\hline Feather & 1305 \\
\hline Abrupt & 678 \\
\hline Step & 108 \\
\hline Plunge & 59 \\
\hline Hinge & 28 \\
\hline Crushed & 14 \\
\hline Unclear (e.g. Distal Retouch) & 86 \\
\hline
\end{tabular}

Table 5 shows the termination types of unbroken flakes (including retouched flakes). It demonstrates that abrupt terminations are very common in the Arcadia Valley assemblage. Figure 8 shows that proportions of abrupt terminations increase in correlation with the number of dorsal flake scar directions, and that they are the most common termination for flakes that have dorsal flake scars from three or four directions.

\section{Flake Typology}

At the outset of the data collection exercise, it was decided to employ a typology for classifying complete flakes. Flake typologies must be used with caution because, while certain knapping techniques and reduction strategies have been demonstrated by replication to 


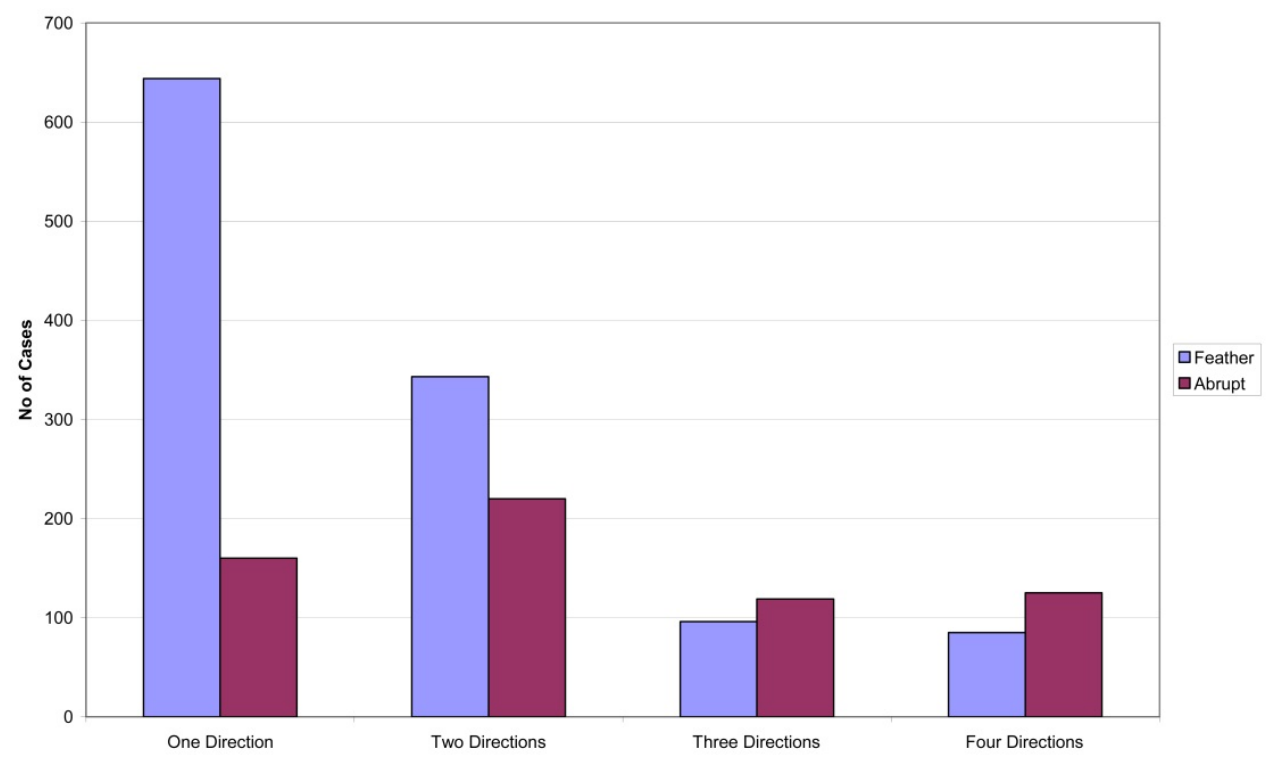

Figure 8. Frequency of feather and abrupt terminations on unbroken flakes (including retouched flakes), sorted according to number of dorsal flake scar directions.

Table 6. Classification of Arcadia Valley unbroken flakes (including retouched flakes) according to flake type. Definitions of these flake types can be found in Cutting Edge Archaeology (2013).

\begin{tabular}{|l|c|c|c|}
\hline & \multicolumn{2}{|c|}{ Maximum Dimension } & \\
\hline & $<\mathbf{3 0 m m}$ & $>\mathbf{2 9 m m}$ & Total \\
\hline Levallois Flake Type 1 & $17(1.6 \%)$ & $34(2.8 \%)$ & $51(2.2 \%)$ \\
\hline Levallois Flake Type 2 & $11(1 \%)$ & $30(2.5 \%)$ & $41(1.8 \%)$ \\
\hline Recurrent Levallois Flk & $1(0.1 \%)$ & $6(0.5 \%)$ & $7(0.3 \%)$ \\
\hline Levallois Point & $8(0.8 \%)$ & $19(1.6 \%)$ & $27(1.2 \%)$ \\
\hline Shark's Tooth Flake & $0(0 \%)$ & $2(0.2 \%)$ & $2(0.1 \%)$ \\
\hline Eclat Debordant & $3(0.3 \%)$ & $33(2.7 \%)$ & $36(1.6 \%)$ \\
\hline Blade & $20(1.9 \%)$ & $52(4.3 \%)$ & $72(3.2 \%)$ \\
\hline Core Tablet $^{*}$ & $44(4.1 \%)$ & $90(7.4 \%)$ & $134(5.9 \%)$ \\
\hline Contact Removal Flake $^{*}$ & $8(0.8 \%)$ & $5(0.4 \%)$ & $13(0.6 \%)$ \\
\hline Adze Flake & $1(0.1 \%)$ & $4(0.3 \%)$ & $5(0.2 \%)$ \\
\hline Bipolar Flake $^{*}$ & $5(0.5 \%)$ & $3(0.2 \%)$ & $8(0.4 \%)$ \\
\hline Flake with Detchmt Scar $^{*}$ & $2(0.2 \%)$ & $4(0.3 \%)$ & $6(0.3 \%)$ \\
\hline Eraillure Flake $^{*}$ & $1(0.1 \%)$ & $0(0 \%)$ & $1(0.05 \%)$ \\
\hline Non Diagnostic Flake & $943(88.6 \%)$ & $934(76.8 \%)$ & $1877(82.3 \%)$ \\
\hline Total $^{*}$ & $1064(100 \%)$ & $1216(100 \%)$ & $2280(100 \%)$ \\
\hline
\end{tabular}

produce characteristic flakes (Andrefsky 2001:6; Odell 2003:121), similar flakes can often be produced by other methods (e.g. Ohnuma 1995). I have noted that these concerns underlined the critique of the use of Bordes' typology in isolation to determine whether assemblages were the product of Levallois technology. It is therefore important to use flake typologies in conjunction with other lines of evidence.

Table 6 shows the distribution of unbroken flakes (including retouched flakes) according to flake type. Some of these flake types are considered diagnostic of Levallois flaking methods. Here they have been defined more narrowly than in European typological schemes, to reduce the risk that products of other techniques might be classified within these types.

A Type 1 Levallois Flake is a complete flake that is plano-convex in section and symmetrical (usually ovoid) in plan. Its thickest point must be in the centre and it must have radial (centripetal) dorsal scar patterning. Fifty-one flakes in the assemblage met this definition (Figure 9b-h). A further seven cases were Recurrent Levallois Flakes, which are Type 1 Levallois flakes with scars of previous predetermined flakes overlapping the radial dorsal scar patterning (Figure 9a).

A Type 2 Levallois Flake has a similar definition to a Type 1 Levallois Flake, but instead of requiring all of the lateral and distal convexities to be established by radial flake scars, they are established by a combination of predetermining flake scars and pre-existing convex surfaces. Forty-one flakes in the assemblage were classified as Type 2.

A Levallois Point is a complete flake with a Y-shaped central dorsal ridge formed by intersecting flake scars, and lateral margins that taper to a point at the distal end. The flake is symmetrical (triangular) in plan and the central dorsal ridge coincides with the axis of percussion. Twenty-seven Levallois points were identified in the Arcadia Valley assemblage (Figure 9i-j). Two other points were classed as shark's tooth flakes. A Shark's Tooth Flake is a variant of a Levallois point with a characteristic shark's tooth shape that is formed because, prior to detachment, the platform is isolated by removing two corner flakes across the platform surface (Moore 2003a:27). 

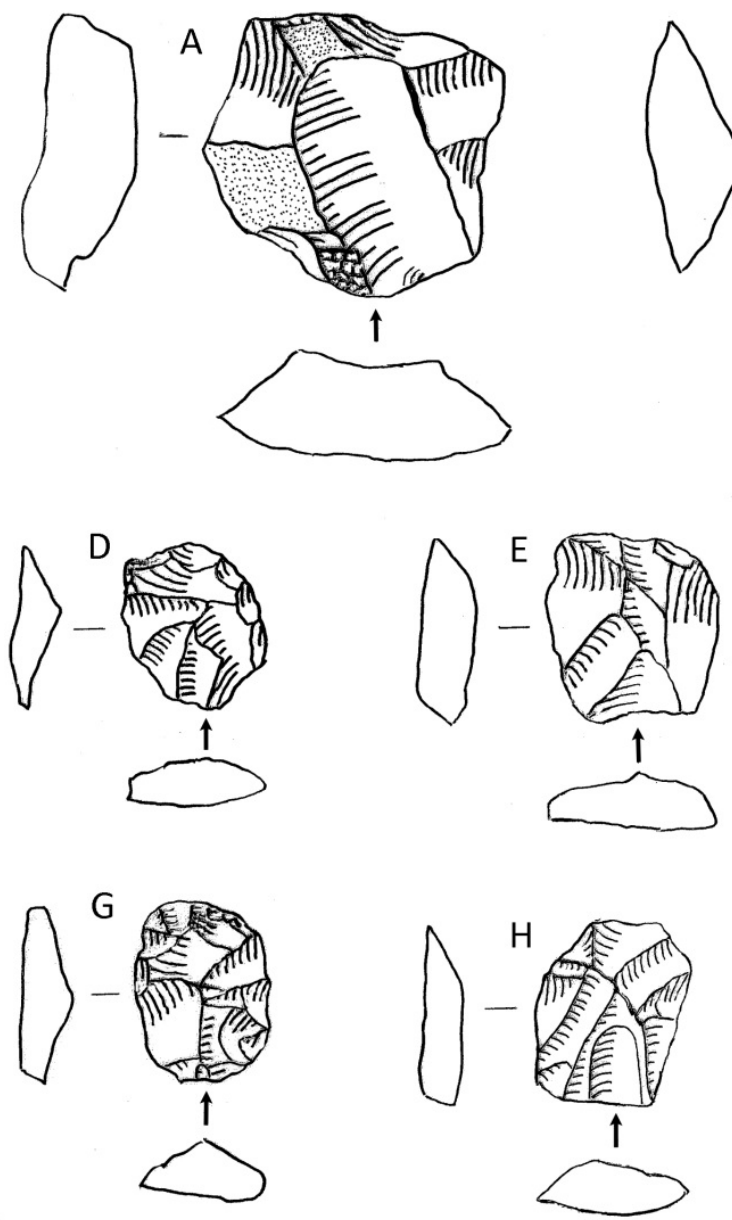
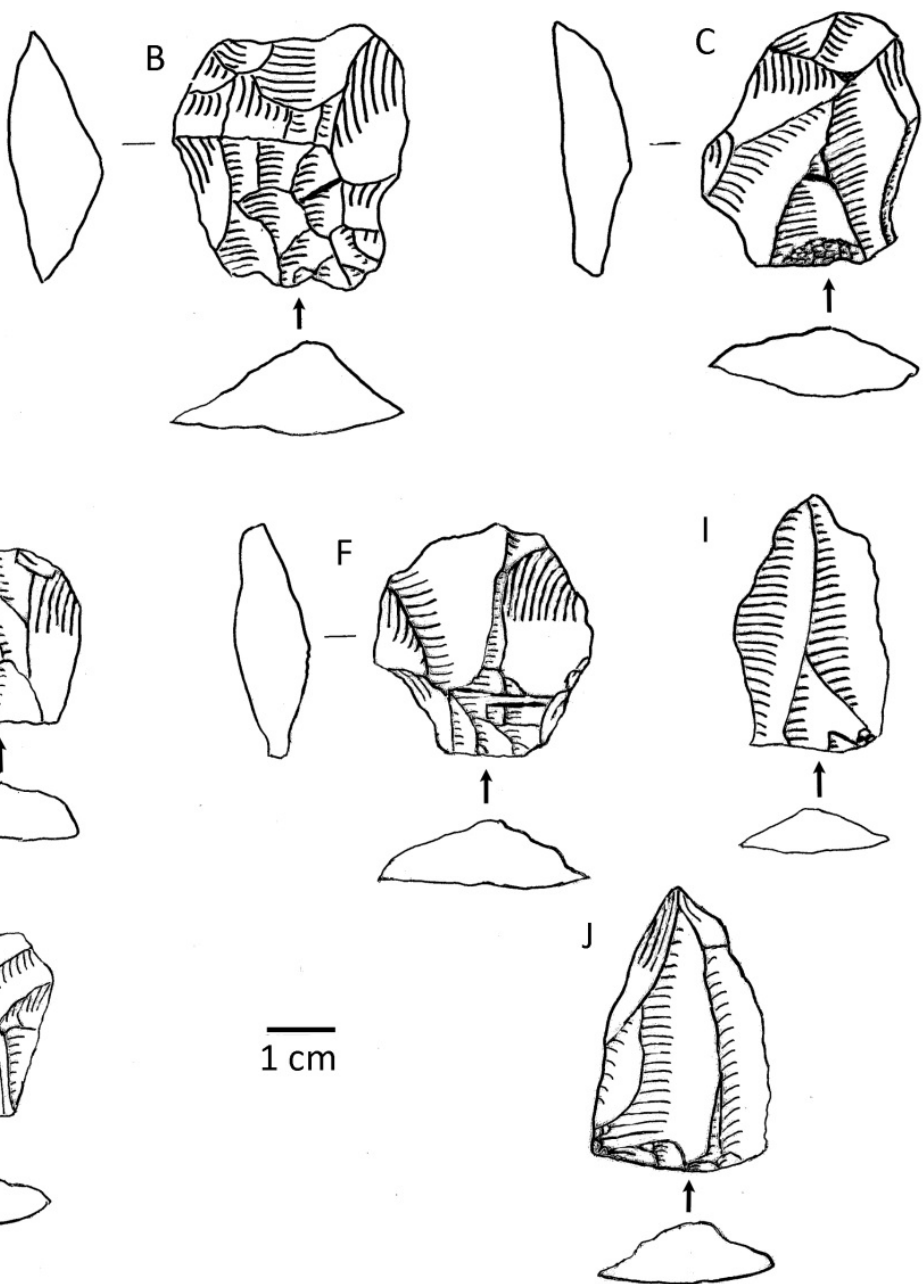

Figure 9. a: recurrent Levallois flake, b-h: type 1 Levallois flakes, i-j: Levallois points.

Seventy-two complete blades were identified in the assemblage. A blade was defined as a flake more than twice as long as it is wide, with parallel or slightly converging edges, and one or more ridges parallel to its long axis, giving it a triangular or trapezoidal crosssection (Bar-Yosef and Kuhn 1999:323). As noted in the discussion of cores types, blades in the Arcadia Valley were produced by a number of reduction methods, including Levallois, conical, pyramidal and burin blade core methods.

The last flake type of interest is the Éclats Débordant. Éclats débordants are a common flake type in Old World systematics but they have been defined in various ways. In this study we impose a fairly rigid definition, requiring that they be flakes that are triangular in plan due to the presence of a steep dorsal ridge that is the remnant corner of a core face. They are often cited as characteristic products of Levallois reduction sequences (e.g. Bar-Yosef and Dibble 1995:xi; Debénath and Dibble 1994:52-55) and in some schemes are considered a special type of predetermined blank (Van Peer 1992:65). However, they are not an exclusive Levallois product (Wallace 2006). Thirty-six éclats débordants were identified in the Arcadia Valley assemblage.

Flakes of these types comprise about $10 \%$ of all complete flakes in the assemblage. When we focus only on flakes with a maximum dimension of $30 \mathrm{~mm}$ or more, the proportion increases to about $14 \%$. While these contributions to the assemblage are moderate, their definitions have been restricted to very idealised forms. From observations of predetermined flake scars on the Arcadia Valley Levallois cores, it is clear that raw material imperfections or lack of precision by the knapper often affected the shape of the flake in an adverse manner. These flakes would probably be classed as non-diagnostic in the Arcadia Valley flake typology. It also should be noted that even in assemblages formed exclusively by Levallois core reduction, predetermined Levallois flakes are usually a minor component. For example, Ohnuma (1995:259) replicated five Levallois cores and produced six predetermined Levallois flakes (including one failure) from a total of 235 debitage pieces.

\section{Summary}

Because it incorporates a range of hypothetical reduction scenarios, the Arcadia Valley core reduction sequence model can identify the presence of core reduction methods, but on its own it can only provide very broad estimates of the relative frequency of each method. Therefore, multiple lines of additional evidence have been drawn upon to provide a more precise estimate of the contribution of Levallois and discoidal core reduction methods to the Arcadia Valley assemblage (cf. Carr and Bradbury 2011:306-307). When considered in combination, this evidence suggests that Levallois and discoidal methods may be responsible for close to $50 \%$ of the artefacts in the assemblage. 


\section{Platform Facetting in Arcadia Valley Levallois Technology}

Facetted platforms are those which are shaped by multiple negative flake scars that originate from the edge of the platform that intersects with the core face. They are usually distinguished from dihedral platforms, which consist of two intersecting surfaces forming a single central ridge, and polyhedral platforms, which consist of more than two surfaces (usually intersecting flake scar remnants) that do not originate from the edge of the platform that intersects with the core face (Bradley and Sampson 1986:35-36). Platforms may also be plain, exhibiting a single surface which may be cortical or the remnants of a single flake scar. These platform types are usually applied to the classification of flakes, but can also be applied to some extent to some core types.

It was noted above that platform facetting is a common but non-obligatory feature of Levallois core reduction. In fact, the significance of platform facetting has been a recurring theme in debates over the definition of Levallois technology. In response to early suggestions that platform facetting should be an intrinsic part of the definition, Bordes (1950) used both archaeological and experimental evidence to argue that Levallois flakes could have unfacetted platforms (Schlanger 1996:250). This was further clarified by Kelley (1954), who conducted extensive refittings of Levallois assemblages from northern France and concluded that 'the most important question is not the presence or absence of facets, but rather the angle of the striking platform in relation to the splitting plane of the flake' (Kelley 1954:151 cited in Schlanger 1996:237). This view has subsequently been supported by a number of other workers (Delagnes 1995:201; Sellet 1995:33). Hence Van Peer (1995:8) has stressed that the platform preparation integral to the Levallois process 'does not necessarily mean faceting'. The platform angle can be adjusted through facetting of the striking platform, the striking surface, or both.

It is also often overlooked that, due to the use of nonmarginal hard hammer percussion, the platforms of Levallois predetermined flakes are sometimes crushed or broken. For example, in Ohnuma’s (1995:259) replication experiments, three of the six predetermined flakes that he detached had broken platforms.

Despite this, facetted platforms are common in most Levallois assemblages. This is probably because in addition to controlling the platform angle, they do provide other benefits, such as developing a localised convexity which promotes greater precision of the striking blow (Lenoir and Turq 1995:253; Meignen 1995:366; Schlanger 1996:237). The relatively low incidence of platform facetting in Arcadia Valley Levallois reduction is a matter that warrants further attention.

Firstly, it should not be assumed that the recognition of facetted platforms is a straightforward process. In Australia, lithic raw materials are generally more coarse grained than those found in Europe, and stone artefacts found in surface assemblages are frequently weathered to some degree. It is often difficult to discern the orientation of all negative flake scars on flake platforms. On Levallois cores, remnant platforms from the detachment of predetermined flakes only retain part of the platform surface, and may be removed or modified by subsequent flaking.
Nevertheless, the evidence strongly suggests that platform facetting was only occasionally included in Arcadia Valley Levallois core reduction methods. Few of the Levallois cores exhibit clear evidence of facetting on the platforms of predetermined flakes (Figure 3). Only $15.9 \%$ of the flakes classified as likely Levallois products (type 1 and 2 Levallois flakes, recurrent Levallois flakes, Levallois points, sharks tooth flakes and éclats débordants) exhibited clear facetted platforms. Among these individual flake types, Levallois points (29.6\%) recorded the highest frequency of facetted platforms. While the likely Levallois products exhibited a higher frequency of facetted platforms than other Arcadia Valley flakes (Table 7), the frequency of facetted platforms is still much lower than that found in most Levallois assemblages.

This low frequency of platform facetting is an example of the technological variation that is possible within the framework of Boëda's volumetric concept of Levallois technology (e.g. Usik et al. 2013). It does not preclude the inferred core reduction processes from being properly classified as Levallois methods, but it does narrow down the possible interpretations of the strategic objectives of Levallois technology in the Arcadia Valley context. A traditional interpretation of the Levallois points and blades - that they were predesigned, intended products of the reduction sequence - is quite plausible. However, the low incidence of facetting on Levallois flakes and the frequency of slightly asymmetrical predetermined flake scars on Levallois flake cores strongly suggest a lack of precision in the production of flakes. One possible explanation for this was foreshadowed earlier in this paper; that the reduction of Levallois flake cores in the Arcadia Valley may be an example of Levallois as a continuous reduction sequence, with predetermined flakes struck for core maintenance purposes rather than as primary intended products (Davidson and Noble 1993:376; Sandgathe 2004). Alternatively, the lack of evidence of Levallois technology in neighbouring regions, and in Australia generally, could suggest that the Arcadia Valley Levallois was an innovation in progress, perhaps discontinued before the most efficient technical aspects of its application could be established.

\section{Discussion}

The approach taken to characterising core reduction in this study is one that acknowledges the theoretical constraints of working with undated open site lithic assemblages. There is a great deal that is unknown about the chronological structure of the Arcadia Valley lithic assemblage. We can argue that the majority of its components were likely to have been deposited during the last 4000-5000 years, but there is little evidence to discern whether the artefacts accumulated steadily over this period or whether the intensity of artefact deposition was punctuated by discrete events (e.g. Holdaway et al. 2005).

Therefore, the construction of a model that emphasises the diversity of possible core reduction methods is not intended to characterise the technological flexibility of a single population, but rather to table the variation that is reflected in the assemblage. Equifinality of some technological processes implies that multiple explanations 
Table 7. Platform types of flakes classed as likely Levallois products, and other flakes.

\begin{tabular}{|l|c|c|}
\hline \multicolumn{1}{|c|}{ Platform Type } & Likely Levallois Products & Other Flakes \\
\hline Facetted & $26(15.9 \%)$ & $229(10.8 \%)$ \\
\hline Missing & $21(12.8 \%)$ & $308(14.6 \%)$ \\
\hline Polyhedral & $14(8.5 \%)$ & $137(6.5 \%)$ \\
\hline Plain Cortical & $16(9.8 \%)$ & $173(8.2 \%)$ \\
\hline Plain Non-Cortical & $82(50 \%)$ & $1221(57.8 \%)$ \\
\hline Other & $5(3 \%)$ & $45(2.1 \%)$ \\
\hline Total & $164(100 \%)$ & $2113(100 \%)$ \\
\hline
\end{tabular}

are possible, and so many of the links between core reduction stages are hypothetical. The model errs on the side of complexity in order to ensure that all possible reduction scenarios are tabled. The model then serves as a baseline framework, from which numerous hypothetical scenarios can be extracted and tested.

One aspect of the model that has been tested in this study is the relative contribution of Levallois and discoidal methods to the assemblage when compared with other methods, particularly informal core reduction. The use of multiple lines of evidence suggested that Levallois and discoidal methods may account for close to half of the assemblage. Based on the small number of cores in the long core and burin blade core categories, it appears that prismatic and burin blade core methods were practiced in the Arcadia Valley but they were responsible for only small numbers of artefacts in the assemblage. This suggests that informal core reduction methods probably account for up to half of the assemblage. Yet even if this is a correct summary of the variation of core reduction methods represented in the Arcadia Valley assemblage, it does not begin to explain the causes of that variation.

A number of factors may be responsible for variation in core reduction methods, including time (Soressi and Geneste 2011:340-341). The key to resolving the uncertainties of time averaging in an artefact assemblage is to develop competing hypotheses about the temporal characteristics of an assemblage that can be tested with independent data sets. For example, it is possible that the assemblage conflates evidence of core reduction methods that are characteristic of different timeframes. Under this scenario, if a narrower timeframe were represented in the assemblage, there would be less variation. Perhaps if the assemblage were restricted to a hundred year period around $3000 \mathrm{BP}$, it might be dominated by evidence of prismatic or burin blade core reduction.

Fortunately, hypotheses about the temporal characteristics of the Arcadia Valley core reduction methods are very amenable to testing, because there are a significant number of artefact assemblages that have been excavated from radiocarbon dated, stratified rockshelter sites in the nearby central Queensland highlands. Together these sites document two very distinct transitions in stone artefact technology in the region. Importantly though, these transitions have mainly been defined by shifts to the production of particular artefact types and by changes in artefact densities. Relatively little attention has been paid to the core reduction methods or other techniques responsible for the production of these characteristic artefacts. Thus while it is generally accepted that some form of microblade technology was employed in the Small Tool Industry $(\sim 4300-2000$ BP $)$ in conjunction with microlith production (Morwood 1984:357), almost nothing is known of core reduction methods used in the scraper-based industries that preceded and followed the Small Tool Industry.

It is therefore reasonable to hypothesise that the formal reduction methods that are most prevalent in the Arcadia Valley core reduction sequence model, the Levallois and discoidal methods, are an unrecognised defining feature of the Recent Industry that replaced the Small Tool Industry about 2000 years ago. This hypothesis can be tested by applying the core typology used in this study to the central Queensland highlands assemblages. Even a simple comparison of dorsal flake scar directions in Small Tool Industry and Recent Industry assemblages may help to shed light on this question, and provide additional evidence of timesensitive artefact attributes. Any additional evidence of this nature will greatly enhance our ability to interpret the massive numbers of undateable stone artefact open sites in the region.

Alternatively, it may transpire that Levallois and discoidal methods were not employed in the highlands. The stone artefacts recovered from highlands rockshelter sites were usually manufactured from rocks obtained from quarried outcrops or downslope scree, rather than waterworn cobbles (Webb et al. 2013). It is possible that one of the reasons Levallois and discoidal methods were employed in Australia was because they were well-suited to lithic material in cobble form. The Levallois methods employed in the Kimberley and at Camooweal, like those of the Arcadia Valley, were focused on the reduction of pebbles and cobbles (Dortch and Bordes 1977:3; Moore 2003a).

\section{Conclusion}

This study has shown that with the right combination of theory and systematics, core reduction sequence modelling can help provide the baseline structural evidence that is necessary to develop testable hypotheses about the relative influence of reduction methods at particular times and places. Evidence of geographical or temporal variation in core reduction methods may provoke different types of explanations depending on one's theoretical perspective (Moore 2013), but first and foremost the variation signifies cultural differences. An interest in identifying cultural variation, regardless of its cause, ought to be something that unites all archaeologists.

\section{Acknowledgements}

I gratefully acknowledge the opportunity given to me to conduct lithic research in the Arcadia Valley by the traditional owners, the Karingbal People. In particular I thank Charles Stapleton for his ongoing support of archaeological research in the area and John Hoare, Raymond Saltner, Fred Stapleton and Katrina Cutting for their interest and assistance while I was working in the valley. Thanks to all of the other Karingbal field 
representatives who participated in the research project, and special thanks to Lavina Saltner and Jordan Comollatti for their help in washing and classifying artefacts. I have also benefitted from the hard work and good humour of my archaeological colleagues engaged in the fieldwork, including Phil Habgood, James Robinson, Xavier Carah and Joe Borg. Thanks also to Ann Wallin and Tim Gall from Archaeo Cultural Heritage Services for introducing me to the project. The photograph in Figure 2 was provided by Phil Habgood. Chris Clarkson and Mark Moore provided very helpful comments on a previous draft of this paper. In conducting the analysis, I have also benefitted from discussions or correspondence with Simon Greenwood, Trudy Doelman, Jamie Reeves and Nicola Stern.

\section{References}

Akerman, K. 1976 Notes on the experimental manufacture of long blades and points by percussion flaking. University of Queensland Occasional Papers in Anthropology 6:117-128.

Akerman, K. 2007 To make a point: Ethnographic reality and the ethnographic and experimental replication of Australian macroblades known as leilira. Australian Archaeology 64:23-34.

Akerman, K., R. Fullagar and A. van Gijn 2002 Weapons and wunan: Production, function and exchange of Kimberley points. Australian Aboriginal Studies 1:14-42.

Andrefsky, W. 2001 Emerging directions in debitage analysis. In W. Andrefsky (ed.), Lithic Debitage: Context, Form, Meaning, pp.2-14. Salt Lake City: University of Utah Press.

ARCHAEO Cultural Heritage Services 2010 Cultural Heritage Investigation, Pipeline Corridor, Santos GLNG Project Arcadia Valley, Central Queensland. Unpublished report to Karingbal Endorsed Parties and the Santos GLNG Project.

ARCHAEO Cultural Heritage Services 2011 Cultural Heritage Mitigation Program, Pipeline Corridor, Santos GLNG Project Arcadia Valley, Central Queensland. Unpublished report to Karingbal Endorsed Parties and the Santos GLNG Project.

Ballin, T.B. 2012 The Levallois-like approach of Late Neolithic Britain: A discussion based on finds from the Stoneyhill project, Aberdeenshire. In A. Saville (ed.), Flint and Stone in the Neolithic Period, pp.37-61. Oxford: Oxbow Books.

Bar-Yosef, O. and H.L. Dibble 1995 Preface. In H.L. Dibble and O. Bar-Yosef (eds), The Definition and Interpretation of Levallois Technology, pp.ix-xiii. Madison: Prehistory Press.

Bar-Yosef, O. and S.L. Kuhn. 1999 The big deal about blades: Laminar technologies and human evolution. American Anthropologist 101:322-338.

Baumler, M.F. 1995 Principles and properties of lithic core reduction: Implications for Levallois technology. In H.L. Dibble and O. Bar-Yosef (eds), The Definition and Interpretation of Levallois Technology, pp.11-23. Madison: Prehistory Press.

Beaton, J.M. 1977 Dangerous Harvest: Investigations in the Late-Prehistoric Occupation of Upland South-East Central Queensland. Unpublished PhD thesis, Australian National University, Canberra.

Beaton, J.M. 1991a Excavations at Rainbow Cave and Wanderer's Cave: Two rockshelters in the Carnarvon Range, Queensland. Queensland Archaeological Research 8:3-32.

Beaton, J.M. 1991b Cathedral Cave: A rockshelter in Carnarvon Gorge, Queensland. Queensland Archaeological Research 8:33-84.
Boëda, E. 1995 Levallois: A volumetric construction, methods, a technique. In H.L. Dibble and O. Bar-Yosef (eds), The Definition and Interpretation of Levallois Technology, pp.41-68. Madison: Prehistory Press.

Boëda, E., Y.M. Hou, H. Forestier, J. Sarel and H.M. Wang 2013 Levallois and non-Levallois blade production at Shuidonggou in Ningxia, north China. Quaternary International 295:191-203.

Bordes, F. 1950 Principes d'une méthode d'étude des techniques de débitage et de la typologie du Paléolithique ancient et moyen. L'Anthropologie 54:19-34.

Bordes, F., C. Dortch, C. Thibault, J-P. Raynal and P. Bindon 1983 Walga Rock and Billibilong Spring: Two archaeological sequences from the Murchison Basin, Western Australia. Australian Archaeology 17:1-26.

Bradley, B. and C.G. Sampson 1986 Analysis by replication of two Acheulian artefact assemblages. In G.N. Bailey and P. Callow (eds), Stone Age Prehistory: Studies in Memory of Charles McBurney, pp.29-45. Cambridge: Cambridge University Press.

Carr, P.J. and A.P. Bradbury 2011 A perspective on the foundation and future of the organization of technology. Paleoanthropology 2011:305-319.

Chazan, M. 2001 Bladelet production in the Aurignacian of La Ferrassie (Dordogne, France). Lithic Technology 26:16-28.

Clarkson, C. 2007 Lithics in the Land of the Lightning Brothers: The Archaeology of Wardaman Country, Northern Territory. Terra Australis 25. Canberra: ANU E Press.

Clarkson, C., S. Jones and C. Harris 2012 Continuity and change in the lithic industries of the Jurreru Valley, India, before and after the Toba eruption. Quaternary International 258:165-179.

Cochrane, G.W.G. 2011 An Analysis of Stone Artefacts from the Arcadia Valley, Central Queensland. Unpublished report to Archaeo Cultural Heritage Services Pty Ltd., The Gap.

Cochrane, G.W.G. 2013 An Analysis of Stone Artefacts from the Springwood Study Area, South Central Queensland. Unpublished report to Archaeo Cultural Heritage Services Pty Ltd., The Gap.

Cochrane, G.W.G., T. Doelman and A.I.R. Herries 2012a Analysis of Stone Artefacts from the Arcadia Valley, Central Queensland. Progress Report on Geoarchaeological Studies. Unpublished report to Archaeo Cultural Heritage Services Pty Ltd., The Gap.

Cochrane, G.W.G., P.J. Habgood, T. Doelman, A.I.R. Herries and J.A. Webb 2012b A progress report on research into stone artefacts of the southern Arcadia Valley, central Queensland. Australian Archaeology 75:104-109.

Cotterell, B. and J. Kamminga 1987 The formation of flakes. American Antiquity 52(4):675-708.

Cundy, P. 1977 An Analysis of Burins from New England and Capertee. Unpublished BA (Hons) thesis, Australian National University, Canberra.

Cutting Edge Archaeology 2013 Guide to Stone Artefact Attributes and their Relevance to Archaeological Research Questions. Retrieved 8 April 2013 from http://www.cearchaeology.com.au/documents/artefact_attrib ute_guide.pdf.

Davidson, I. and W. Noble 1993 Tools and language in human evolution. In K. Gibson and T. Ingold (eds), Tools, Language and Cognition in Human Evolution, pp.363-388. Cambridge: Cambridge University Press. 
Debénath, A. and H.L. Dibble 1994 Handbook of Paleolithic Typology: Lower and Middle Paleolithic of Europe. Vol. 1. Philadelphia: University of Pennsylvania Press.

Delagnes, A. 1995 Variability within uniformity: Three levels of variability within the Levallois system. In H.L. Dibble and O. Bar-Yosef (eds), The Definition and Interpretation of Levallois Technology, pp.201-211. Madison: Prehistory Press.

Dibble, H.L. 1989 The implications of stone tool types for the presence of language during the Lower and Middle Paleolithic. In P. Mellars and C. Stringer (eds), The Human Revolution: Behavioural and Biological Perspectives on the Origin of Modern Humans, pp.415-433. Edinburgh: Edinburgh University Press.

Dibble, H.L. 1995 Biache Saint-Vaast, Level IIA: A comparison of analytical approaches. In H.L. Dibble and O. Bar-Yosef (eds), The Definition and Interpretation of Levallois Technology, pp.93-116. Madison: Prehistory Press.

Doelman, T. and G.W.G. Cochrane in press Design theory and the Australian tula adze. Asian Perspectives.

Dortch, C.E. 1972 An archaeological site in the Chichester Range, Western Australia: Preliminary account. Journal of the Royal Society of Western Australia 55:65-72.

Dortch, C.E. 1977 Early and late stone industrial phases in Western Australia. In R.V.S. Wright (ed.), Stone Tools as Cultural Markers: Change, Evolution and Complexity, pp.104-132. Prehistory and Material Culture Series 12. Canberra: Australian Institute of Aboriginal Studies.

Dortch, C.E. and F. Bordes 1977 Blade and Levallois technology in Western Australian prehistory. Quartär 2728:1-19.

Finlayson, B. and C. Kenyon 2007 Lake Nuga Nuga: A leveedammed lake in central Queensland, Australia. Geographical Research 45:246-261.

Galloway, R.W. 1967a Geomorphology of the Isaac-Comet area. In CSIRO, Lands of the Isaac-Comet Area, Queensland, pp.77-88. Land Research Series 19. Melbourne: CSIRO.

Galloway, R.W. 1967b Geology of the Isaac-Comet area. In CSIRO, Lands of the Isaac-Comet Area, Queensland, pp.6876. Land Research Series 19. Melbourne: CSIRO.

Hiscock, P. 1986 Technological change in the Hunter River valley and the interpretation of late Holocene change in Australia. Archaeology in Oceania 21(1):40-50.

Hiscock, P. 1993 Bondaian technology in the Hunter Valley, New South Wales. Archaeology in Oceania 28(2):65-76.

Hiscock, P. and C. Clarkson 2000 Analysing Australian stone artefacts: An agenda for the twenty first century. Australian Archaeology 50:98-108.

Holdaway, S. and M. Douglass 2012 A twenty-first century archaeology of stone artifacts. Journal of Archaeological Method and Theory 19:101-131.

Holdaway, S.J., P.C. Fanning and J. Shiner 2005 Absence of evidence or evidence of absence? Understanding the chronology of indigenous occupation of western New South Wales, Australia. Archaeology in Oceania 40(2):33-49.

Holdaway, S. and N. Stern 2004 A Record in Stone: The Study of Australia's Flaked Stone Artefacts. Canberra: Aboriginal Studies Press.
Horne, G. 1921 Aboriginal Stone Implements of South-Eastern Victoria. Hobart: Australasian Association for the Advancement of Science.

Jaubert, J. and C. Farizy 1995 Levallois debitage: Exclusivity, absence or coexistence with other operative schemes in the Garonne Basin, southwestern France. In H.L. Dibble and O. Bar-Yosef (eds), The Definition and Interpretation of Levallois Technology, pp.227-248. Madison: Prehistory Press.

Kamminga, J. 1982 Over the Edge: Functional Analysis of Australian Stone Tools. Occasional Papers in Anthropology 12. St Lucia, QLD: Anthropology Museum, University of Queensland.

Kelley, H. 1954 Contribution à l'étude de la technique de la taille levalloisienne. Bulletin de la Société Préhistorique Française 51:149-169.

Lenoir, M. and A. Turq 1995 Recurrent centripetal debitage (Levallois and discoidal): Continuity or discontinuity? In H.L. Dibble and O. Bar-Yosef (eds), The Definition and Interpretation of Levallois Technology, pp.249-256. Madison: Prehistory Press.

L’Oste-Brown, S., L. Godwin and C. Porter 1998 Towards an Indigenous Social and Cultural Landscape of the Bowen Basin: Bowen Basin Aboriginal Cultural Heritage Project. Cultural Heritage Monograph Series 2. Brisbane: Queensland Department of Environment.

Luebbers, R. 1978 Meals and Menus: A Study of Change in Prehistoric Coastal Settlements in South Australia. Unpublished $\mathrm{PhD}$ thesis, Australian National University, Canberra.

Lycett, S.J. and C.J. Norton 2010 A demographic model for Palaeolithic technological evolution: The case of East Asia and the Movius line. Quaternary International 211:55-65.

McCarthy, F.D. 1964 The archaeology of the Capertee Valley, New South Wales. Records of the Australian Museum 26:197-246.

Meignen, L. 1995 Levallois lithic production systems in the Middle Paleolithic of the Near East: The case of the unidirectional method. In H.L. Dibble and O. Bar-Yosef (eds), The Definition and Interpretation of Levallois Technology, pp.361-379. Madison: Prehistory Press.

Miller, R. 1982 Levallois cores from the Upper Euphrates Valley, Syria in the third millenium BC. Paléorient 8:105107.

Moore, M.W. 2000a Technology of Hunter Valley microlith assemblages, New South Wales. Australian Archaeology 51:28-39.

Moore, M.W. 2000b Lithic technology in Tasmania. Archaeology in Oceania 35(2):57-73.

Moore, M.W. 2003a Flexibility of stone tool manufacturing methods on the Georgina River, Camooweal, Queensland. Archaeology in Oceania 38(1):23-36.

Moore, M.W. 2003b Australian Aboriginal biface reduction techniques on the Georgina River, Camooweal, Queensland. Australian Archaeology 56:22-34.

Moore, M.W. 2004 The tula adze: Manufacture and purpose. Antiquity 78:61-73. 
Moore, M.W. 2010 Lithic Analysis for the South East Queensland Correctional Precinct Development at Gatton, Millers Rd, Spring Creek, Gatton LGA, Southeast Queensland. Unpublished report to Turnstone Archaeology and Jagara Daran Pty Ltd.

Moore, M.W. 2013 Simple stone flaking in Australasia: Patterns and implications. Quaternary International 285:140-149.

Newman, K. and M.W. Moore 2013 Ballistically anomalous stone projectile points in Australia. Journal of Archaeological Science 40:2614-2620.

Morwood, M.J. 1981 Archaeology of the Central Queensland Highlands: The stone component. Archaeology in Oceania 16(1):1-52.

Morwood, M.J. 1984 The prehistory of the Central Queensland Highlands. Advances in World Archaeology 3:325-380.

Mulvaney, D.J. and E.B. Joyce 1965 Archaeological and geomorphological investigations on Mt. Moffat Station, Queensland, Australia. Proceedings of the Prehistoric Society 31:147-212.

Odell, G.H. 2003 Lithic Analysis. New York: Springer.

Ohnuma, K. 1995 Analysis of debitage pieces from experimentally reduced "classical Levallois" and "discoidal" cores. In H.L. Dibble and O. Bar-Yosef (eds), The Definition and Interpretation of Levallois Technology, pp.257-266. Madison: Prehistory Press.

Olausson, D. 2010 Experimental flintknapping replication - A valuable method of archaeological analysis. In H.G. Nami (ed.), Experiments and Interpretation of Traditional Technologies: Essays in Honor of Errett Calahan, pp.37-55. Buenos Aires: Ediciones de Arqueologia Contemporánea.

Otte, M. 1995 The nature of Levallois. In H.L. Dibble and O. Bar-Yosef (eds), The Definition and Interpretation of Levallois Technology, pp.117-124. Madison: Prehistory Press.

Pelcin, A.W. 1997 The formation of flakes: The role of platform thickness and exterior platform angle in the production of flake initiations and terminations. Journal of Archaeological Science 24:1107-1113.

Sandgathe, D.M. 2004 Alternative interpretation of the Levallois reduction technique. Lithic Technology 29:147-159.

Schlanger, N. 1996 Understanding Levallois: Lithic technology and cognitive archaeology. Cambridge Archaeological Journal 6:231-254.

Sellet, F. 1993 Chaine operatoire: The concept and its applications. Lithic Technology 18:106-112.

Sellet, F. 1995 Levallois or not Levallois, does it really matter? Learning from an African case. In H.L. Dibble and O. BarYosef (eds), The Definition and Interpretation of Levallois Technology, pp.25-39. Madison: Prehistory Press.

Shiner, J., S. Holdaway, H. Allen and P. Fanning 2007 Burkes Cave and flaked stone assemblage variability in western New South Wales, Australia. Australian Archaeology 64:3545.

Shott, M.J. 2003 Chaîne opératoire and reduction sequence. Lithic Technology 28:95-105.
Shott, M.J., J.M. Lindly and G.A. Clark 2011 Lessons from refitting cores from WHS 623x, an Upper Paleolithic site in Jordan. Paleoanthropology 2011:320-333.

Soressi, M. and J-M. Geneste 2011 Studying techniques to reveal past societies in an evolutionary perspective. Paleoanthropology 2011:334-350.

Terradas, X. 2003 Discoid flaking method: Conception and technological variability. In M. Peresani (ed.), Discoid Lithic Technology: Advances and Implications, pp.19-31. BAR International Series 1120. Oxford: Archaeopress.

Texier, P-J. and I. Francisco-Ortega 1995 Main technological and typological characteristics of the lithic assemblage from Level I at Bérigoule, Murs-Vaucluse, France. In H.L. Dibble and O. Bar-Yosef (eds), The Definition and Interpretation of Levallois Technology, pp.213-226. Madison: Prehistory Press.

Tostevin, G.B. 2011. Special issue: Reduction sequence, chaîne opératoire, and other methods: The epistemologies of different approaches to lithic analysis: Introduction. Paleoanthropology 2011:293-296.

Tuffreau, A. 1995 The variability of Levallois technology in northern France and neighbouring areas. In H.L. Dibble and O. Bar-Yosef (eds), The Definition and Interpretation of Levallois Technology, pp.413-427. Madison: Prehistory Press.

Usik, V.I., J.I. Rose, Y.H. Hilbert, P. Van Peer and A.E. Marks 2013 Nubian complex reduction strategies in Dhofar, southern Oman. Quaternary International 300:244-266.

Van Peer, P. 1992 The Levallois Reduction Strategy. Monographs in World Archaeology 13. Madison: Prehistory Press.

Van Peer, P. 1995 Current issues in the Levallois problem. In H.L. Dibble and O. Bar-Yosef (eds), The Definition and Interpretation of Levallois Technology, pp.1-9. Madison: Prehistory Press.

Wallace, I.J. 2006 Review of 'Examining the Levallois Reduction Strategy from a Design Theory Point of View’ by D.M. Sandgathe. Paleoanthropology 2006:51-53.

Webb, J., B. Finlayson, G. Cochrane, T. Doelman and M. Domanski 2013 Silcrete quarries and artefact distribution in the Central Queensland Highlands, eastern Australia. Archaeology in Oceania 48(3):130-140.

Witter, D.C. 1988 From butchering caribou to butchering stone. In B. Meehan and R. Jones (eds), Archaeology with Ethnography: An Australian Perspective, pp.33-41. Canberra: Australian National University.

Witter, D.C. 1992 Regions and Resources. Unpublished PhD thesis, Australian National University, Canberra.

Young, R.W. and R.A.L. Wray 2000 Contribution to the theory of scarpland development from observations in central Queensland, Australia. The Journal of Geology 108:705719. 